\title{
Why Do Different Short- sellers Pay Different Loan Fees? A Market-wide Analysis
}

Fernando Chague

RODRIGO DE-LOSSO

Alan De Genaro

BRUNO GIOVANNETTI 


\author{
DEPARTMENT OF ECONOMICS, FEA-USP \\ WORKING PAPER № 2015-17
}

\title{
Why Do Different Short-sellers Pay Different Loan Fees? A Market-wide Analysis
}

\author{
Fernando Chague (fchague@usp.br) \\ Rodrigo De-Losso (ㄹelosso@usp.br) \\ Alan De Genaro (adg@usp.br) \\ Bruno Giovannetti (bcg@usp.br)
}

\begin{abstract}
:
High loan fees generate short-selling constraints and, therefore, reduce price efficiency. Despite the importance of loan fees, empirical evidence on their determinants is scarce. Using a market-wide deal-by-deal data set on the Brazilian equity lending market which uniquely identifies borrowers, brokers, and lenders, we are able to construct a proxy of search costs at the borrower-stock-day level. We find that - for the same stock, on the same day - borrowers with higher search costs pay significantly higher loan fees. Our results suggest that regulators should encourage the use of a centralized lending platform to reduce search costs in the lending market.
\end{abstract}

Keywords: short sale constraints; equity lending; borrower search costs; OTC.

JEL Codes: G12; G29. 


\title{
Why Do Different Short-sellers Pay Different Loan Fees? A Market-wide Analysis*
}

\author{
Fernando Chague ${ }^{\dagger}$ Rodrigo De-Losso ${ }^{\ddagger}$ \\ Alan De Genaro ${ }^{\S}$ Bruno Giovannetti
}

July 30, 2015

\begin{abstract}
High loan fees generate short-selling constraints and, therefore, reduce price efficiency. Despite the importance of loan fees, empirical evidence on their determinants is scarce. Using a market-wide deal-by-deal data set on the Brazilian equity lending market which uniquely identifies borrowers, brokers, and lenders, we are able to construct a proxy of search costs at the borrower-stock-day level. We find that - for the same stock, on the same day - borrowers with higher search costs pay significantly higher loan fees. Our results suggest that regulators should encourage the use of a centralized lending platform to reduce search costs in the lending market.
\end{abstract}

*We thank Rafael Benini, Elias Cavalcante, Giulia Iori, Marcos Nakaguma, José Carlos de Souza Santos, Marcos Eugênio da Silva, Leonardo Viana and seminar participants at University of São Paulo, Getúlio Vargas Foundation and Insper for their comments and suggestions. We are responsible for any remaining errors.

${ }^{\dagger}$ Department of Economics, University of Sao Paulo, Brazil. E-mail: fchague@usp.br

Department of Economics, University of Sao Paulo, Brazil. E-mail: delosso@usp.br

$\S$ Department of Economics, University of Sao Paulo, Brazil. E-mail: adg@usp.br

`Department of Economics, University of Sao Paulo, Brazil. E-mail: bcg@usp.br 


\section{Introduction}

A short-seller is constrained if the loan fee exceeds the expected fall in the stock price. High loan fees therefore generate short-selling constraints. Short-selling constraints are not desirable for two reasons: they cause stock overpricing (Danielsen and Sorescu (2001), Jones and Lamont (2002), Nagel (2005), Chang et al. (2007), Stambaugh et al. (2012) and Blocher et al. (2013)) and they reduce price efficiency (Asquith et al. (2005), Nagel (2005), Cao et al. (2007), Saffi and Sigurdsson (2011), Engelberg et al. (2012) and Boehmer and Wu (2013)). Despite these adverse effects of loan fees on the stock market, there is sparse empirical literature on the determinants of loan fees, mostly due to lack of data. ${ }^{1}$ In this paper we use a unique data set to show that loan fees depend on borrower search costs.

Loan fees should be close to zero in a frictionless lending market. Lenders have long investment horizons and do not care about short-term variations in stock prices (D'Avolio, 2002), so that lending a stock for a short period is costless. Competition among lenders would thus drive loan fees to zero. This is not observed in the data, however. Loan fees vary substantially over time and can be quite high (D'Avolio (2002), Reed (2013) and Engelberg et al. (2013)).

Duffie, Gârleanu and Pedersen (2002; hereafter DGP) provides a model that explains why loan fees can be high. In their model borrowers face search costs that limit the frequency with which they can find lenders, allowing lenders to act as local monopolists and thereby charge positive loan fees. In this setting loan fees are increasing in borrower search costs.

Kolasinski, Reed and Ringgenberg (2013; hereafter KRR) is the only paper which empirically studies the relationship between loan fees and search costs. They use proxies for search costs which vary across stocks and time, such as firm size, bid-ask spread, and measures of stock concentration among lenders. Consistent with the theoretical predictions in DGP, they find that both loan fee levels and loan fee dispersion are increasing in these stock-specific measures of search costs. ${ }^{2}$

\footnotetext{
${ }^{1}$ The equity lending market in the US and other countries is over-the-counter (OTC), with transactions usually only visible to the parties involved. As we discuss below, although the Brazilian lending market is also OTC all loan deals must be registered at BM\&FBOVESPA, which acts as the central counterpart. In this paper we use the BM\&FBOVESPA market-wide data.

${ }^{2}$ DGP's model does not predict loan fee dispersion, since it includes no heterogeneity among lenders and borrowers. As discussed by KRR, industrial organization models with sequential search produce price dispersion when there is heterogeneity among investors.
} 
However, search costs are not just stock-specific: different borrowers face different search costs when searching for the same stock. Consider two borrowers, A and B. Borrower A has very good relationships in the lending market: she is a good client of big brokers who in turn know many active lenders. By contrast, borrower B is connected to a single broker, who has few connections to active lenders. These two borrowers will face different search costs for the same stock.

The main contribution of this paper is to be the first to study the relationship between loan fees and search costs at the borrower level. We test two hypotheses: H1) the higher the search costs a borrower faces, the higher the loan fees she pays; and H2) the higher the search costs that borrowers face, the higher the loan fee dispersion among these borrowers. We find strong favorable evidence for both $\mathrm{H} 1$ and $\mathrm{H} 2$.

Measuring borrower-specific search costs is challenging. As the above example suggests, one has to measure the importance of each lender in the market as well as the strength of the relationships between borrowers, brokers, and lenders. For that to be possible one needs to (i) observe all loan deals in the market and (ii) uniquely identify borrowers, brokers, and lenders over time. The data sets used so far in the literature allow neither (i) nor (ii).

Our data set enables both (i) and (ii). Every transaction in the Brazilian lending market is cleared through BM\&FBOVESPA, which keeps a record of all loan deals closed in Brazil. Our data set contains information on the loan quantity, loan fee, investor type, borrower ID, broker ID, and lender ID for all loan deals in the Brazilian stock market from January 2008 to July $2011 .^{3}$

We construct our borrower-specific measure of search costs based on DGP description of the lending market dynamics. In a typical transaction, a potential short-seller contacts her broker asking for a particular stock to borrow. The broker then searches for a potential lender of the stock. Hence, locating a stock will be easier for a borrower who has good relationships with brokers that, in turn, have good relationships with active lenders of the stock.

Based on that, we say that a borrower has low search costs if she is "well-connected" to brokers that are "well-connected" to active lenders. We say a borrower is well-connected to a

\footnotetext{
${ }^{3}$ The investor-type variable classifies borrowers as either "individuals" or "institutions". The ID variables in our data uniquely identifies each market participant and is time-invariant. These IDs are "fake", i.e., anonymous.
} 
broker if she is an important customer of the broker. We say a broker is well-connected to a lender if it is responsible for a high share in the loan deals of the lender. Since our data set allows us to follow each market participant through time, we are able to compute (a) how well-connected each borrower is to each broker, (b) how well-connected each broker is to each lender, and (c) how active each lender is in the lending market of each stock. From (a), (b), and (c) we calculate the Borrower Connection $(B C)$, a variable that is borrower-specific, stock-specific, and varies over time. The $B C$ variable is constructed so that it is high when the borrower is well-connected to brokers which in turn are well-connected to active lenders of a stock. $B C$ should therefore be negatively related to borrower search costs.

We perform a number of empirical exercises that relate $B C$ to loan fees. We first run deal-by-deal panel regressions with loan fees on the left hand side and $B C$ on the right hand side. We find that low-connected borrowers pay significantly higher loan fees. We also allow for nonlinear effects by separating borrowers into three groups (high-, medium-, and low- $B C$ ) and comparing the average loan fee in each group. We find that borrowers in the low- $B C$ group pay $14.5 \%$ higher loan fees than borrowers in the high- $B C$ group.

Second, we use direct measures of loan fee dispersion (loan fee standard deviation and range across deals for the same stock) to test whether loan fee dispersion is higher among low connected borrowers. We find that loan fee standard deviation and loan fee range among borrowers in the low $B C$-group are respectively $46 \%$ and $135 \%$ higher than those among borrowers in the high- $B C$ group.

Lastly, we refine the analysis by studying the in-broker variation of loan fees. We run the same regressions using only deals closed within a single broker - the largest one in terms of deals. The conclusions are the same as before: we find that on the same day, for the same stock, this single broker intermediates deals with different loan fees which are decreasing in borrower $B C$.

Importantly, all results are robust across sub-samples. To account for unobserved borrower specific effects that may correlate with both $B C$ and loan fees, all regressions are run within sub-samples of borrowers that share similar characteristics with respect to investor type, traded volume, and frequency of trades. In doing so, we estimate the effect of $B C$ on loan fees across deals closed by similar borrowers. Considering only institutions, we find that a low- $B C$ institution pays an $8.5 \%$ higher loan fee than a high- $B C$ institution. Considering only frequent borrowers, we find that a low- $B C$ frequent borrower pays a $10.9 \%$ higher loan 
fee than a high- $B C$ frequent borrower. Finally, considering only large borrowers, we find that a low- $B C$ large borrower pays a $9.8 \%$ higher loan fee than a high- $B C$ large borrower.

The paper closest in purpose to ours is KRR. Using a unique data set involving 12 important lenders in the US market, KRR shows that at high borrowing demand levels positive shocks to demand result in higher loan fees. They moreover show that the effect of borrowing demand on loan fees is greater for stocks associated with high levels of search costs, which is consistent with DGP. In doing so KRR inaugurates the empirical evidence of the effects of search costs on loan fees. Our paper continues this investigation. In addition to stock-specific search costs, we find that search costs at the borrower level are also important drivers of loan fees.

Engelberg et al. (2013) also empirically investigates loan fees. They run predictive regressions to explain loan fees conditional on a number of variables such as past loan fees, institutional ownership, lending offers, and the federal funds rate. Their goal is to dynamically evaluate short-selling risks. Prado (2015) tests another implication of the DGP model, namely that stock prices incorporate expected future lending income (i.e., the loan fee, acting as a dividend, increases the stock's price). She finds that institutions buy shares in response to an increase in loan fees, which is consistent with DGP.

This paper also relates to a more general literature on OTC markets. Duffie et al. (2005) and Duffie et al. (2007) provide a theory of dynamic asset pricing that directly addresses search and bargaining in general OTC markets, with the goal of evaluating the effects of search frictions on asset prices. Another set of papers focuses on the "percolation" of information which is of common interest throughout OTC markets (Duffie and Manso (2007), Duffie et al. (2009) and Duffie et al. (2010)). Zhu (2012) also presents a dynamic model of opaque OTC markets where sellers search for buyers. On the empirical side, Ang et al. (2013) and Eraker and Ready (2015) study the stock returns of firms that trade on OTC markets. Our results suggest that opacity in OTC markets induce important search frictions that affect prices: market participants with higher search costs pay higher prices for the same asset. Regulators should therefore encourage the use of electronic trading platforms to reduce opacity and hence search costs in these markets.

This paper is organized as follows. Section 2 explains the Brazilian stock lending market and describes our data set. Section 3 documents the existence of loan fee dispersion. Section 4 specifies our measure of borrower-specific search costs. Section 5 presents the empirical 
results. Section 6 exhibits the effects of a lending platform on loan fees. Finally, Section 7 presents our concluding remarks.

\section{Stock Lending in Brazil}

The securities lending market in Brazil is regulated by the Brazilian Securities Commission $(\mathrm{CVM}) .{ }^{4}$ All transactions are mediated by BM\&FBOVESPA-registered brokers, who are responsible for bringing together stock borrowers and stock lenders. All securities listed on the exchange are eligible for lending. Crucially for us, in Brazil every lending transaction must be registered in the BM\&FBOVESPA lending system. This contrasts with most other lending markets, which are decentralized and in which data about lending deals are only partially available.

According to D'Avolio (2002) and Reed (2013), in the US the loan fee is implicitly given by the "rebate" rate when loans are cash-collateralized. The rebate rate is the interest rate that the lender pays the borrower in exchange for holding the cash-collateral; it is lower than the federal funds rate. The higher the difference between the rebate rate and the fed fund rate, the higher the implicit loan fee. If the borrower posts instead Treasury securities as collateral, she simply pays the lender an explicit loan fee. The average loan fee of an easily-borrowed stock ranges between $0.05 \%$ and $0.25 \%$ per year. Stocks with high loan fees are called specials; their rebate rates may even be negative. Approximately $9 \%$ of stocks are specials, with an average loan fee of about 4.3\% (D'Avolio, 2002). The overall average loan fee in the US is therefore $0.52 \% .^{5}$

All loan deals in Brazil are collateralized with Treasury securities. ${ }^{6}$ Hence there are no "rebate" rates and all loan deals are negotiated in terms of explicit loan fees. In our sample the average loan fee, including all stocks (both specials and non-specials), is $2.75 \%$ per year - much higher than in the US.

\footnotetext{
${ }^{4}$ The stock lending market in Brazil has grown substantially. During 2011, the last year in our data set, more than US\$ 400 billion were loaned in over 1.4 million transactions, corresponding to one-third of the Brazilian market's total capitalization. In that year 290 different stocks were traded in the lending market. ${ }^{5} 0.52 \%=0.09 \times 4.3 \%+0.91 \times 0.15 \%$.

${ }^{6}$ The collateral is deposited at BM\&FBOVESPA, which acts as the central counterpart to all lending transactions.
} 
One possible explanation for the higher Brazilian loan fees is the higher stock market volatility. According to DGP, given the existence of borrower search costs, lenders are able to charge short sellers a loan fee that is equal to some fraction of the short sellers' expected profit, which should be increasing in the expected volatility of the asset price. Hence the higher the expected volatility, the higher the loan fee (Engelberg et al. (2013) provides empirical evidence consistent with this). Indeed, stock market volatility is much higher in Brazil than in the US. During our sample period (January 2008 - July 2011) the average implied volatility for the US (VIX) was $17.50 \%$ whereas in Brazil it was $23.72 \%$ (that is, about $35 \%$ higher). ${ }^{7}$

The higher Brazilian risk-free rate may also contribute to the higher loan fees. Engelberg et al. (2013) document that loan fees are proportional to the risk-free rate. Indeed, the ratios between loan fees and risk-free rates in Brazil and in the US are similar. ${ }^{8}$

\subsection{Data Set}

We observe all of the 2,302,360 lending deals closed in the Brazilian stock market from January 2008 to July 2011. For each lending deal we have information on the loan quantity, loan fee, borrower type (institution or individual), borrower ID, broker ID, and lender ID. These ID variables uniquely and anonymously identifies each market participant and are time-invariant.

The numbers of distinct borrowers and lenders in the lending market are shown in Table 1. In 2008 there were 17,435 distinct borrowers and 3,471 distinct lenders. The number of investors increased over the subsequent years: there were 22,166 borrowers and 3,416 lenders in 2009; 24,809 borrowers and 6,785 lenders in 2010; and 16,515 borrowers and 8,103 lenders in the first seven months of 2011.

[Table 1 about here]

\footnotetext{
${ }^{7}$ Astorino et al. (2015) calculates the implied volatility for Brazil.

${ }^{8}$ The ratio in the US is $21 \%=0.52 \% / 2.5 \%$ (using $2.5 \%$ as the average federal funds rates). In Brazil, the ratio is $25 \%=2.75 \% / 10.9 \%$ (where $10.9 \%$ is the average Brazilian risk-free rate, the Selic rate, during our sample period).
} 
We apply two filters to our data set. First, because the main regressions of this paper use the standard deviation of loan fees for each stock in each week, we need a sufficiently large number of loan deals per stock per week. We therefore restrict our sample to liquid stocks in the lending market. We say a stock is liquid if it was loaned during every week of our sample. We end up with 55 stocks which jointly account for 1,417,964 loan deals.

The second filter is as follows. According to Brazilian law the tax treatment of "interest on equity" differs by investor type: individual investors pay a tax rate of $15 \%$ while financial institutions are exempt. As a result, on days around the ex-date of interest on equity a tax arbitrage trade between individuals and financial institutions commonly occurs: (i) individuals lend shares to financial institutions at a higher loan fee; (ii) financial institutions receive the interest on equity and pay no taxes; (iii) financial institutions transfer to individuals the net value (i.e., excluding taxes) that individuals would receive from interest on equity; and (iv) individuals then receive a higher loan fee, while financial institutions profit by $15 \%$ of the interest on equity minus the loan fee. Since loan fees from these arbitrage deals are artificially high, we exclude all loan deals that were closed in a six-day window around the ex-date. The final sample encompasses 1,338,936 loan deals involving the 55 most liquid stocks.

\section{Evidence of Loan Fee Dispersion}

Opaque markets are characterized by high search costs. This is the case for the stock lending market, which is OTC. As discussed by KRR, sequential search cost models predict that markets with high search costs exhibit high price dispersion. In this Section we show that the Brazilian lending market has significant loan fee dispersion.

We measure loan fee dispersion as the standard deviation of the annualized loan fee of all deals for the same stock on a given day. Figure 1 shows the time-series of this variable for the 4 stocks with the largest number of loan deals in our sample, namely VALE5 (131,441 deals), PETR4 (107,263 deals), GGBR4 (78,916 deals), and BBDC4 (70,311). Each point in the figure corresponds to the loan fee dispersion of a given day. As can be seen, dispersion varies greatly during the period. Days with dispersion around $0.5 \%$ p.y. are common for the four stocks, and the variable often reaches $1 \%$ p.y., which is high when compared with the 
average loan fee levels reported on Table 2 for these stocks (VALE5: 0.47\%; PETR4: 0.77\%; GGBR4: $2.19 \%$; BBDC4: $0.54 \%$ ).

[Figure 1 and Table 2 about here]

Figure 2 and Table 2 show the time-series average of the loan fee dispersion for each stock in our sample. Stocks are alphabetically ordered. Note that average dispersion is high and varies across stocks.

[Figure 2 about here]

Figure 3 shows the cross-sectional average of the loan fee dispersion for each day in our sample. High dispersion is frequent in the Brazilian stock lending market.

[Figure 3 about here]

\section{Borrower-specific Search Costs}

Our goal is to relate (i) the loan fee that a borrower pays to (ii) the search cost she faces when searching for the stock in the lending market. As shown by KRR, loan fee level and dispersion are increasing in various proxies for search costs. The proxies KRR use, however, are firmspecific (market capitalization, liquidity, and the fragmentation of its share lending market) and do not completely capture search costs at the borrower level. Our main contribution is to use a borrower-specific proxy for search cost.

Our measure of search cost relies on the idea that the stock lending market is a "relationshipbased market", as discussed in DGP and KRR. The typical lending transaction proceeds as follows. The borrower communicates her broker(s) that she is looking for a particular stock to borrow. The broker then has to search for a potential lender of the stock. 
Based on such a dynamics, we assume that a borrower has low search costs if she is "well-connected" to a broker who in turn is "well-connected" to active lenders. A borrower is well-connected to a broker if the borrower is an important customer of this broker. A broker is well-connected to a lender if the broker accounts for a high share of the lender's loans.

We explain with an example. Investor $I$ wants to borrow shares of stock XYZ. Investor $I$ frequently borrows stocks (from any firm) with the intermediation of Broker $B$. Broker $B$ is in turn responsible for a large share of the loans that Lender $L$ makes (with respect to all stocks loaned by Lender $L$ ). Lender $L$ is an active lender of stock XYZ. Will Investor $I$ face high search costs in this case? We suppose not. In contrast, Investor $I$ will face higher search costs if (i) Investor $I$ is not an important client of Broker $B$ and/or (ii) Broker $B$ is responsible only for a small share of the loans that Lender $L$ makes and/or (iii) Lender $L$ is a small lender of stock XYZ.

Since our detailed data set allows us to follow each market participant through time, we are able to compute (a) how well-connected each borrower is to each broker, (b) how well-connected each broker is to each lender, and (c) how active each lender is in the lending market of each stock. We use (a), (b), and (c) to calculate the search cost of each borrower. We now explain the details of this calculation.

\subsection{Broker Reach}

To calculate the ability of broker $i$ to locate a specific stock $s$ to borrow on day $t$, which we call Broker Reach ${ }_{i, s, t}$, we follow three steps. First, we measure the importance of each lender $j$ in the lending market of stock $s$ on day $t$ as

$$
\text { Lender Importance }_{j, s, t}=\frac{\text { shares }_{j, s, t}}{\text { total shares }_{s, t}}
$$

where shares $_{j, s, t}$ is the number of shares lent by lender $j$ of stock $s$ during the 90 -day period ${ }^{9}$ previous to day $t$, and total shares $s_{s, t}$ is the total number of shares of stock $s$ that were loaned in the same period.

\footnotetext{
${ }^{9}$ The 90-day window was arbitrarily chosen and the first to be considered. All results are robust to 60-day and 120-day windows and are available upon request.
} 
We then quantify the strength of the relationship of broker $i$ with lender $j$ on day $t$ as

$$
\text { BrokerLender Relation }_{i, j, t}=\frac{\text { deal }_{i, j, t}}{\text { total deals }_{j, t}}
$$

where deals $s_{i, j, t}$ is the total number of loan deals closed, considering all stocks, between broker $i$ and lender $j$ in the 90 -day period previous to day $t$, and total deal $s_{j, t}$ is the total number of loan deals made by lender $j$ in the same period.

The assumption here is that if broker $i$ recently closed many loan deals with lender $j$, then they have a good relationship. Note that measured this way the strength of the relationship between broker $i$ and lender $j$ is not stock-specific.

Finally, the ability of broker $i$ to locate stock $s$ on day $t$ is given by

$$
\text { BrokerReach }_{i, s, t}=\sum_{j=1}^{J} \text { Lender Importance }_{j, s, t} \times \text { BrokerLender Relation }_{i, j, t}
$$

where $J$ is to total number of lenders.

BrokerReach ${ }_{i, s, t}$ will be high for a broker that, on day $t$, has good relationships with important lenders of stock $s$. By construction, the cross-broker sum

$$
\sum_{i=1}^{I} \text { Broker Reach }_{i, s, t}
$$

is equal to one for any $s=1, \ldots, S$ and every $t=1, \ldots, T$.

\subsection{Borrower Connection}

If a borrower has good relationships with brokers with high BrokerReach on stock $s$, it should be easy for her to find the stock. That is, this well-connected borrower will have low search cost for this stock. Based on this idea we calculate the connection of borrower $k$ with respect to stock $s$ on day $t$, which we call BorrowerConnection B $, s, t$, in two steps.

We first quantify the strength of the relationship between borrower $k$ and each broker $i$ on day $t$ as

$$
\text { Borrower Broker Relation }_{k, i, t}=\frac{\text { deal }_{k, i, t}}{\text { totaldeals }_{i, t}}
$$


where deals $s_{k, i, t}$ is the number of loan deals (considering any stock) between borrower $k$ and broker $i$ in the 90-day period previous to day $t$, and total deals $s_{i, t}$ is the total number of loan deals made by broker $i$ in the same period.

The connection of borrower $k$ with respect to stock $s$ on day $t$ is then

$$
B C_{k, s, t}=100 \times\left(\sum_{i=1}^{I} \text { Broker Reach }_{i, s, t} \times \text { BorrowerBrokerRelation }_{k, i, t}\right)
$$

We multiply the right-hand side by 100 so that $B C_{k, s, t}$ is expressed in percentage points. By construction, for any $s=1, \ldots, S$ and at any $t=1, \ldots, T$ the sum of $B C_{k, s, t}$ across all $k$ borrowers for a given stock $s$ and on given day $t$ is equal to 100:

$$
\sum_{k=1}^{K} B C_{k, s, t}=100
$$

$B C_{k, s, t}$ is a time-varying and stock-specific variable which is decreasing in the search cost of borrower $k$ : a high value means that the borrower has strong relationships with brokers with high reach, that is, with brokers which have strong relationships with active lenders of the stock. Figure 4 presents a diagram that illustrates the steps involved in the construction of $B C .{ }^{10}$

[Figure 4 about here]

We note that $B C_{k, s, t}$ is not the market share of the borrower on the stock. Consider for instance a short-seller that during the 90-day window did not borrow any stock $s$. She may still have a high $B C_{k, s, t}$ if she closed many deals on other stocks with brokers which have high Broker Reach with respect to stock $s$. We further discuss the relation between $B C$ and market share in Section 5.6.

\footnotetext{
${ }^{10}$ We could frame our measure within the theory of graphs and networks. Borrowers, brokers and lenders are the nodes of the network. Brokers and lenders are connected through the variable BrokerLender Relation (a weighted edge) and the variable BrokerReach is a measure of the centrality of brokers in the brokerslenders sub-network. Borrowers and brokers are connected through the variable BorrowerBrokerRelation (a weighted edge) and the variable $B C$ is a measure of the centrality of borrowers in the whole network. A recent treatment of networks can be found in Newman (2010) and a discussion on recent applications of networks in finance can be found in Allen and Babus (2009).
} 
To illustrate the dynamics of our main variable, Figure 5 shows the time-series of $B C$ of four arbitrary frequent borrowers on the four most liquid stocks in the lending market.

[Figure 5 about here]

The top-left plot shows a borrower who had high connections at the beginning of the sample which then decreased over time. This pattern emphasizes the time-variability of $B C$. Note that the connections across the four stocks turn zero and non-zero at the same time. This highlights the difference between $B C$ and market share: it takes a single deal on any stock during the past 90 days for the borrower to become connected with respect to all of the stocks that her broker can reach.

The top-right plot illustrates that $B C$ indeed varies across stocks. This particular borrower is well connected to brokers which, in turn, have strong relationships with important lenders of stock BBDC4. The borrowers represented in the lower plots further illustrate that $B C$ does vary over time and across stocks.

\subsubsection{Borrower Connection by Investor Type}

We observe 51,006 different borrowers who traded at least once between January 2008 and July 2011. We classify borrowers into the following types: individuals, institutions, large, and frequent. The distinction between individuals and institutions comes directly from the original data set. Out of the whole set of borrowers 45,097 are individuals and 5,909 are institutions.

The "large" and "frequent" types are defined as follows. We compute for each borrower the average volume across all her deals. We say that the top $5 \%$ borrowers are "large borrowers". We say moreover that borrowers who traded during more than half of the weeks are "frequent borrowers". Out of the whole set of borrowers 2,551 are large borrowers and 364 are frequent borrowers.

Table 3 exhibits some descriptive statistics on the number of loan deals and on the borrower connection, $B C$, for each type of borrower.

[Table 3 about here] 
Considering all 51,006 borrowers, on average 28 loan deals were made per borrower during the period. The number of deals of each borrower is highly left-skewed: the 1st, 25th, 50th, 75th, and 99th percentiles are respectively 1, 1, 3, 10, and 326 deals. The borrower with the greatest number of deals made 30,885 deals during the period. Considering only the 45,097 individual borrowers, the average borrower made 9 deals and the percentiles are: 1 (1st), 1 (25th), 3 (50th), 9 (75th) and 21 (99th); the greatest individual borrower made 3,579 deals. Considering only the 5,909 institutional borrowers, the average borrower made 167 loan deals and the percentiles are 1 (1st), 2 (25th), 7 (50th), 34 (75th) and 3,484 (99th); the greatest institutional borrower made 30,885 deals. Considering only the 2,551 "large" borrowers", the average borrower made 272 deals and the percentiles are 1 (1st), 2 (25th), 8 (50th), 63 (75th) and 5,222 (99th); the greatest large borrower made 30,885 deals. Finally, considering only the 364 "frequent" borrowers, the average borrower made 1,750 deals and the percentiles are 142 (1st), 354 (25th), 722 (50th), 1,676 (75th) and 18,942 (99th); the greatest frequent borrower made 30,885 deals.

Table 3 also presents descriptive statistics for the $B C$ variable (more precisely, for the borrower's $B C$ average across time and stocks). The statistics show that the $B C$ variable is also highly left-skewed. For all investors, the average $B C$ is $0.003 \%$, percentiles are 0 (1st), 0 (25th), $2 \times 10^{-5 \%}$ (50th), $2 \times 10^{-4 \%}$ (75th) and $0.064 \%$ (99th), and the maximum is $3.86 \%$. Considering only individuals, the average $B C$ is $6 \times 10^{-4 \%}$, percentiles are 0 (1st), 0 (25th), $1 \times 10^{-5 \%}$ (50th), $1 \times 10^{-4 \%}$ (75th) and $0.009 \%$ (99th), and the maximum is $1.28 \%$. Considering only institutions, the average $B C$ is $0.024 \%$, percentiles are 0 (1st), 0 (25th), $1 \times 10^{-4 \%}$ (50th), $0.004 \%$ (75th) and $0.449 \%$ (99th), and the maximum is $3.86 \%$. Considering only large borrowers, the average $B C$ is $0.04 \%$, percentiles are 0 (1st), 0 (25th), $4 \times 10^{-4 \%}$ (50th), $0.01 \%$ (75th) and $0.789 \%$ (99th), and the maximum is $3.86 \%$. Finally, considering only frequent borrowers, the average $B C$ is $0.168 \%$, percentiles are 0 (1st), 0.007 (25th), $0.066 \%$ (50th), $0.149 \%$ (75th) and $1.817 \%$ (99th), and the maximum is $3.86 \%$.

\section{$5 \quad$ Empirical Analysis}

Our goal is to relate the loan fee that a borrower pays with the search costs she faces when looking for the stock in the lending market. We measure search costs via the borrower 
connection variable $B C_{k, s, t}$ introduced in the last Section. This variable is borrower-specific, time-varying and stock-specific. The higher $B C_{k, s, t}$ is, the lower the search costs of borrower $k$ for stock $s$ on day $t$ are.

Since the lending market is OTC, borrowers need to locate lenders, which is costly in the presence of search frictions. Moreover, information on deals such as loan fees is not publicly disclosed. In this setting, theory predicts that borrower search costs affect loan fees. First, the magnitude of the loan fee is increasing in borrower search costs (see DGP). This follows from the "local" monopoly power lenders end up having due to the increasingly segmented market. Furthermore, since lenders may have different marginal costs and face different borrowing demands, higher search costs should also yield loan fee dispersion. We summarize these predictions into two testable hypotheses:

- Hypothesis 1 (H1): the higher the search cost that a borrower faces (i.e., the lower $B C)$, the higher the loan fee she pays;

- Hypothesis 2 (H2): the higher the search cost that borrowers face (i.e., the lower $B C$ ), the higher the loan fee dispersion among these borrowers.

\subsection{Search Costs and Loan Fee Level}

Hypothesis H1 says that borrowers who face higher search costs pay higher loan fees. We test this first by running deal by deal panel regressions where the dependent variable is the loan fee (p.y., in \%) paid by the borrower. The main explanatory variable is $B C_{k, s, t}$

- borrower $k$ 's connection in the lending market for stock $s$ on day $t$. The easier it is for borrower $k$ to find stock $s$ on day $t$, the higher the value of $B C_{k, s, t}$ is. We control the regressions for stock fixed-effects, for day fixed-effects, for the past 5-day stock return, and for the past 5-day stock volatility (stock return standard deviation). Stock fixed-effects are important because search costs can vary across firms, as shown by KRR. Table (4) lays out the regression results.

[Table 4 about here] 
Columns 2 and 3 of Table 4 show the regressions considering all deals from all borrowers. The number of observations (deals) is 1,338,936. In Column 2, the estimated coefficient of the variable $B C$ is -0.057 and significant at the $1 \%$ level. This means that an increase of 1 percentage point in $B C$ decreases the loan fee in 0.057 percentage points. In Column 3 we control for past volatility and past return. The $B C$ coefficient barely changes $(-0.056)$ and remains significant.

Considering only institutions (Columns 4 and 5), we have 931,975 deals in the regression. In Column 4 , the $B C$ coefficient is equal to -0.042 , significant at the $1 \%$ level. Controlling for past volatility and past return (Column 5) does not change the result.

Considering only large borrowers (Columns 6 and 7), we have 648,382 deals in the regression. In this case, the estimate of $B C$ coefficient is equal to -0.051 , also significant at the $1 \%$ level, in both columns.

Finally, considering only frequent borrowers (Columns 8 and 9), we have 606,323 deals in the regression. In this case, the estimate of $B C$ coefficient is equal to -0.040 and significant at the $5 \%$ level in both columns.

The standard deviation of the variable $B C$ is $1 \%$ within all types of borrowers, $1.2 \%$ within institutions, $1.4 \%$ within large borrowers, and $1.4 \%$ within frequent borrowers. The average loan fee is $2.6 \%$ within all types of borrowers, $2.7 \%$ for institutions, $2.7 \%$ for large borrowers, and $2.7 \%$ for frequent borrowers. Hence, considering the estimates from Table 4 , we conclude that a one standard-deviation increase in $B C$, for each restricted sample, generates a decrease in the loan fee relative to its mean equal to $2 \%$ (all borrowers), $2 \%$ (institutions), 3\% (large borrowers) and $2 \%$ (frequent borrowers). We next show that grouping borrowers according to the value of their $B C$ strengthens the effect of search costs on the loan fee levels.

\subsubsection{Non-linear Effect}

We allow for a non-linear effect of $B C$ on the loan fee by estimating three coefficients, one for each of the following groups: low- $B C$, medium- $B C$, and high- $B C$. The grouping is stock- and week-specific. Within each stock-week pair, we rank deals with respect to the borrowers' $B C_{k, s, t}$ and then classify the borrowers as belonging to the low- $B C$ group if $B C_{k, s, t}$ is below the $50 \%$-percentile, to the medium- $B C$ group if $B C_{k, s, t}$ is between the $50 \%$ - 
and the $90 \%$-percentile, and to the high- $B C$ group if $B C_{k, s, t}$ is above the $90 \%$-percentile. We use these thresholds to account for the high left-skewness of $B C$, as shown in Table 3 .

Within each stock-week-group cell, we compute the average loan fee across all deals. We then run panel regressions of this average loan fee within each cell on two dummy variables, High and Low. High has value one if the cell refers to the high- $B C$ group and zero otherwise. Low has value one if the cell refers to the low- $B C$ and zero otherwise. All regressions include both stock and week fixed effects. Column 2 of Table 5 shows the results considering all borrowers. Columns 3 to 5 show the results considering groupings and regressing among institutions, large borrowers, and frequent borrowers.

\section{[Table 5 about here]}

Considering all borrowers (Columns 2), there are 25,323 stock-week-type observations in the regression. The coefficient of the high- $B C$ group is -0.153 , significant at the $1 \%$ level. The coefficient for the low- $B C$ group is 0.186 , significant at the $1 \%$ level. This means that a low- $B C$ borrower pays on average a $14.5 \%$ higher loan fee than a high- $B C$ borrower. ${ }^{11}$

Considering only institutions (Columns 3), there are 25,149 stock-week-type observations in the regression. The coefficient of the high- $B C$ group is -0.157 , significant at the $1 \%$ level, and the coefficient relative to the low- $B C$ group is 0.060 , also significant at the $1 \%$ level. This means that a low- $B C$ institution pays on average a $8.5 \%$ higher loan fee than a high- $B C$ institution. 12

Considering only large borrowers (Columns 4), there are 24,474 stock-week-type observations in the regression. The coefficient of the high- $B C$ group is -0.189 , significant at the $1 \%$ level, and the coefficient relative to the low- $B C$ group is 0.055 , also significant at the $1 \%$ level. This means that a low- $B C$ large borrower pays on average a $9.8 \%$ higher loan fee than a high- $B C$ large borrower. ${ }^{13}$

Finally, considering only frequent borrowers (Columns 5), there are 24,558 stock-weekgroup observations in the regression. The coefficient relative to the high- $B C$ group is -0.213 , significant at the $1 \%$ level, and the coefficient of the low- $B C$ group is 0.066 , also significant

\footnotetext{
${ }^{11} 14.5 \%=\frac{0.186+0.153}{2.34}$, where 2.34 is the average loan fee across all deals closed by high- $B C$ borrowers. $128.5 \%=\frac{0.157+0.06}{2.57}$, where 8.5 is the average loan fee across all deals closed by high- $B C$ institutions. $139.8 \%=\frac{0.189+0.055}{2.50}$, where 2.50 is the average loan fee across all deals closed by high- $B C$ large borrowers.
} 
at the $1 \%$ level. This means that a low- $B C$ frequent borrower pays on average a $10.9 \%$ higher loan fee than a high- $B C$ frequent borrower. ${ }^{14}$

The effect of borrower search costs on the loan fee level is therefore very substantial across all groups. Note that connection matters even within large and frequent borrowers. We next study the relationship between borrower search costs and loan fee dispersion.

\subsection{Search Costs and Loan Fee Dispersion}

Hypothesis H2 says that the higher the search costs that borrowers face (i.e., the lower the $B C$ ), the higher the loan fee dispersion among these borrowers. To test this prediction, we use the weekly data set constructed in Section 5.1.1.

Within each stock-week-type cell we compute two measures of loan fee dispersion: (i) the standard deviation of the loan fee and (ii) the range of the loan fee. We then run panel regressions of both variables on two dummy variables, High and Low, defined as in Section 5.1. As before, we first consider all borrowers and then restrict the sample to institutions, to large borrowers, and to frequent borrowers. All regressions include both stock and week fixed effects. The results are shown in Table 6 .

[Table 6 about here]

Considering all borrowers (Columns 2 and 3), there are 25,252 stock-week-type observations in the regression. For the standard deviation measure (Column 2), the coefficient of the high- $B C$ type is not significant, while the coefficient of the low- $B C$ type is 0.246 and significant at the $1 \%$ level. For the range measure (Column 3 ), the coefficient of the high- $B C$ type is -1.264 , significant at the $1 \%$ level, and the coefficient of the low- $B C$ type is 1.154 , also significant at the $1 \%$ level.

Considering only institutions (Columns 4 and 5), there are 25,097 stock-week-type observations in the regression. For the standard deviation measure (Column 4), the coefficient of the high- $B C$ type is not significant, while the coefficient of the low- $B C$ type is 0.10 , significant at the $1 \%$ level. For the range measure (Column 5), the coefficient of the high- $B C$

\footnotetext{
${ }^{14} 10.9 \%=\frac{0.213+0.066}{2.55}$, where 2.55 is the average loan fee across all deals closed by high- $B C$ frequent borrowers.
} 
type is -0.977 , significant at the $1 \%$ level, and the coefficient of the low- $B C$ type is 0.612 , also significant at the $1 \%$ level.

Considering only large borrowers (Columns 6 and 7), there are 24,474 stock-week-type observations in the regression. For the standard deviation measure (Column 6), both the coefficients for the high- $B C$ and for the low- $B C$ types are not significant. For the range measure (Column 7), the coefficient of the high- $B C$ type is -0.919 , significant at the $1 \%$ level, and the coefficient of the low- $B C$ type is 0.156 , also significant at the $1 \%$ level.

Finally, considering only frequent borrowers (Columns 8 and 9), there are 24,558 stockweek-type observations in the regression. For the standard deviation measure (Column 8), the coefficient of the high- $B C$ type is not significant, while the coefficient of the low- $B C$ type is 0.090 , significant at the $1 \%$ level. For the range measure (Column 9 ), the coefficient of the high- $B C$ type is -1.010 , significant at the $1 \%$ level, and the coefficient for the low- $B C$ type is 0.489 , significant at the $1 \%$ level.

Using the loan fee standard deviation as the proxy for loan fee dispersion, we conclude that (i) among low- $B C$ borrowers there is a higher loan fee dispersion than among mediumand high- $B C$ borrowers; (ii) there is no difference in loan fee dispersions among mediumand high- $B C$ borrowers; and (iii) there is no difference in dispersion across $B C$ types when the sample is restricted to large borrowers.

For the unrestricted sample and for the restricted samples for institutions and frequent borrowers, the difference between the loan fee standard deviation among low- $B C$ borrowers and that of other borrowers is $0.246 \%$ (unrestricted), $0.1 \%$ (institutions), and $0.09 \%$ (frequent borrowers). These numbers are economically significant: the average loan fee standard deviation is $0.53 \%$ (unrestricted), $0.53 \%$ (institutions), and $0.54 \%$ (frequent borrowers). Considering for instance the unrestricted sample, this means that the standard deviation among low- $B C$ borrowers is $46 \%$ higher than the standard deviation among high- $B C$ borrowers. ${ }^{15}$

Using the loan fee range as the proxy for loan fee dispersion, we conclude that (i) there is a higher loan fee dispersion among low- $B C$ borrowers than among medium- $B C$ borrowers and (ii) there is a higher loan fee dispersion among medium- $B C$ borrowers than among high- $B C$ borrowers. These results hold for all regressions. The difference between the loan fee range among low- $B C$ borrowers and medium- $B C$ borrowers is $1.154 \%$ (unrestricted), $0.612 \%$ (institutions), $0.156 \%$ (large borrowers), and $0.489 \%$ (frequent borrowers). The dif-

\footnotetext{
${ }^{15} 46 \%=\frac{0.246 \%}{0.53 \%}$.
} 
ference between the loan fee range among medium- $B C$ borrowers and high- $B C$ borrowers is $1.264 \%$ (unrestricted), $0.977 \%$ (institutions), $0.919 \%$ (large borrowers), and $1.010 \%$ (frequent borrowers). These numbers are economically significant: the average loan fee range is $1.79 \%$ (unrestricted), $1.78 \%$ (institutions), $1.79 \%$ (large borrowers), and $1.74 \%$ (frequent borrowers). Considering for instance the unrestricted sample, this means that the range among low- $B C$ borrowers is $135 \%$ higher than the range among high- $B C$ borrowers. ${ }^{16}$

These estimates confirm that higher borrower search costs yield higher loan fee dispersions. As was the case for the average loan fee, the results still hold within borrower type. In particular, loan fee dispersion increases with search costs even among frequent borrowers.

\subsection{Brokerage Fees}

In a lending transaction the borrower pays the loan fee plus a brokerage fee. In our regressions we considered the loan fee net of this brokerage fee. This is important because brokerage fee may be directly related to $B C$, since the broker may charge lower fees from more important borrowers. Thus, including the brokerage fee in the loan fee would pollute our analysis.

However, understanding how brokerage fee and search costs relate to each other is important in itself: high brokerage fees constrain short-sellers by increasing the costs of borrowing. ${ }^{17}$ Panel A of Table 7 shows the results of the deal-by-deal panel regressions where the dependent variable is the brokerage fee (p.y., in \%) paid by the borrower and the explanatory variable is $B C$. In Panel $\mathrm{B}$ we allow for a nonlinear effect of $B C$ on brokerage fees by grouping borrowers into the high-, medium- and low- $B C$ groups as in Section 5.1. We compute the average brokerage fee within each stock-week-group cell. We then run panel regressions of this average brokerage fee within each cell on the two group dummy variables.

[Table 7 about here]

\footnotetext{
${ }^{16} 135 \%=\frac{1.154 \%+1.264 \%}{1.79 \%}$.

${ }^{17}$ In our sample, the average brokerage fee is $0.22 \%$ p.y. and the median brokerage fee is $0.05 \%$ p.y.. Considering only deals closed by frequent borrowers the average is $0.14 \%$ p.y. and the median is zero. Considering only deals closed by institutions and large borrowers we get similar numbers, the average is $0.15 \%$ p.y. and the median is zero.
} 
The results in Table are consistent with the idea that brokers charge lower fees from high- $B C$ borrowers. In Panel $\mathrm{A}$, the coefficients of the $B C$ variable are always negative and statistically significant at the $1 \%$ level across all samples. Panel B shows that that low$B C$ borrowers pay higher brokerage fees than medium- and high- $B C$ borrowers. Moreover, medium- $B C$ borrowers pay higher brokerage fees than high- $B C$ borrowers. Again, the results hold across all samples.

\subsection{Loan Fee Level vs. Loan Fee Dispersion Across Stocks}

KRR argue that search costs can be stock-specific. For example, it should be relatively costly to search for small cap and illiquid stocks in the lending market. It is therefore interesting to compare loan fee dispersion and loan fee level across the stocks in our sample. If search costs vary at the stock-level then these two variables should be positively related in the cross-section of stocks.

Figure 6 shows a scatter-plot of the stock fixed effects estimated in Column 2 of Table 5 and in Column 2 of Table 6. It clearly shows that stocks with higher loan fee dispersion also have higher loan fee level. This is in line with the results shown in Table VIII of KRR.

[Figure 6 about here]

\subsection{Inside the Top Broker}

We have so far have been measuring loan fee dispersion as the standard deviation and range of the loan fees within stock-day pairs (in Section 3) and within stock-week pairs (in Section 5.2). In this Section we refine these measures by calculating them within a single broker. Consistent with our previous findings, we find that (i) different borrowers pay different loan fees in deals done with the same broker (same stock, same day) and (ii) these differences are related to borrower search costs.

Figure 7 shows all of the 91 brokers in our sample sorted according to the number of deals closed during the entire period. The biggest broker is responsible for 195,512 loan 
deals, twice the number of deals closed by the second-biggest broker $(93,966)$. This volume of data suffices to analyze loan fee dispersion inside this single top broker.

[Figure 7 about here]

We first document the existence of loan fee dispersion by computing the standard deviation of loan fees within stock-day pairs using only deals closed inside the top broker. Figure 8 reports the time-series average of the daily loan fee dispersion for each stock. Figure 9 reports the cross-sectional average of the loan fee dispersion for each day. Both figures show that even inside the same broker there is significant loan fee dispersion. Moreover, loan fee dispersion varies considerably both in the cross-section as in the time-series, consistent with the results in Section 3.

[Figures 8 and 9 about here]

We now run regressions of loan fee level and loan fee dispersion on $B C$, the borrowers' connection variable. ${ }^{18}$ We first test whether the loan fee level is decreasing in $B C$ in a dealby-deal regression. We then test whether loan fee dispersions are higher in groups of low- $B C$ borrowers.

[Table 8 about here]

Table 8 shows the results of the loan fee level regressions. Columns 2 and 3 show the estimates considering all deals closed inside the top broker (a total of 195,512 observations). In Column 2 the coefficient of the $B C$ variable is -0.199 , significant at the $1 \%$ level. This means that an increase of 1 percentage point in $B C$ decreases the loan fee level by 0.199 percentage points. Column 3 shows that these results remain the same after controlling for past volatility and past return.

\footnotetext{
${ }^{18}$ Although the regressions in this Section include only the deals closed by the top broker, $B C$ is a marketwide variable, computed using the full sample, as in Section 4.
} 
Columns 4 and 5 show the estimates considering deals from institutions closed inside the top broker (a total of 25,901 observations). In Column 4, the coefficient of variable $B C$ is -0.155 and significant at the $1 \%$ level. In Column 5 , the results remain after we control for past volatility and past return.

Columns 6 and 7 show the estimates considering deals from large borrowers closed inside the top broker (a total of 14,739 observations). In Column 6, the coefficient of variable $B C$ is -0.129 and significant at the $1 \%$ level. In Column 7 , it becomes -0.126 .

Finally, Columns 8 and 9 show the estimates considering deals from frequent borrowers closed inside the top broker (a total of 15,335 observations). In Column 8, the coefficient of variable $B C$ is -0.123 and significant at the $1 \%$ level. In Column 9 , it becomes -0.125 .

Table 9 presents the results for the loan fee dispersion regressions. The regressions are the same ones shown in Table 6, but with the dependent variables constructed with only the deals closed inside the top broker. Columns 2 and 3 show the estimates considering all borrowers (a total of 5,421 stock-week-type observations). For the standard deviation measure (Column 2), the coefficient relative to the high- $B C$ type is -0.168 , significant at the $1 \%$ level, and the coefficient relative to the low- $B C$ type is 0.002 , not significant. For the range measure (Column 3 ), the coefficient relative to the high- $B C$ type is -1.355 , significant at the $1 \%$ level, and the coefficient relative to the low-connected type is -0.025 , but not significant.

[Table 9 about here]

Considering only institutions (Columns 4 and 5), there are 4,021 stock-week-type observations in the regression. Using the standard deviation measure (Column 4), the coefficient of the high- $B C$ type is -0.221 , significant at the $1 \%$ level, and the coefficient of the low- $B C$ type is 0.067 , significant at the $5 \%$ level. Using the range measure (Column 5 ), the coefficient of the high- $B C$ type is -1.239 , significant at the $1 \%$ level, and the coefficient of the low- $B C$ type is 0.065 , but not significant.

Considering only large borrowers (Columns 6 and 7), there are 2,908 stock-week-type observations. Using the standard deviation measure (Column 6), the coefficient of the high$B C$ type is -0.166 , significant at the $1 \%$ level, and the coefficient of the low- $B C$ type is 0.042 , not significant. Using the range measure (Column 7), the coefficient of the high- $B C$ 
type is -0.820 , significant at the $1 \%$ level, and the coefficient of the low- $B C$ type is -0.017 , but not significant.

Finally, considering only frequent borrowers (Columns 8 and 9), there are 3,431 stockweek-type observations in the regression. For the standard deviation measure (Column 8), the coefficient relative to the high- $B C$ type is -0.150 , significant at the $1 \%$ level, and the coefficient of the low- $B C$ type is equal to 0.093 , also significant at the $1 \%$ level. For the range measure (Column 9), the coefficient of the high- $B C$ type is -0.889 , significant at the $1 \%$ level, and the coefficient of the low- $B C$ type is 0.067 , but not significant.

These results show that borrowers with different search costs pay different loan fees in deals closed even inside the same broker. We take this as a strong evidence in favor of hypotheses $\mathrm{H} 1$ and $\mathrm{H} 2$.

\subsection{Borrower Connection and Borrower Market Share}

Let share $_{k, s, t}$ be the market share of borrower $k$ with respect to stock $s$ in the 90-day window previous to day $t$. Recall that $B C_{k, s, t}$ measures how costly it is for borrower $k$ to search for stock $s$ on day $t$. This Section discusses the relation between $B C_{k, s, t}$ and share $_{k, s, t}$ and shows that share $_{k, s, t}$ explains neither loan fee levels nor loan fee dispersions. Hence $B C_{k, s, t}$ encompasses more information than the borrower market share share $_{k, s, t}$

The following example illustrates how these two variables differ. Consider an investor who during the last 90 days borrowed a large volume of firm A's stock from a large broker. During this period the borrower called the broker almost every day searching for stock A, and closed large loan deals. Assume that today this same borrower calls the broker, but now searching for stock B. Although the borrower has closed no deals on stock B in the last 90 days, it is likely to be relatively easy for him to search for stock B: he is after all a good client of the broker, which is therefore highly motivated to do a good job looking for stock B among its clients. In other words, the borrower's search cost on stock B is not just a function of his market share in the stock.

Although conceptually different, $B C_{k, s, t}$ and share $_{k, s, t}$ should be positively related to each other: both should be high for active borrowers. To confirm this intuition we run share $_{k, s, t}$ on $B C_{k, s, t}$ using our deal-by-deal data set. We first use the full sample and then restrict it 
to institutions, to large borrowers, and to frequent borrowers. Table 10 displays the results. The estimates show that the relation between $B C_{k, s, t}$ and share $_{k, s, t}$ is, as expected, positive and highly significant.

[Table 10 about here]

Although $B C$ and share are positively related, $B C$ should contain more relevant information to explain the loan fee level and dispersion, as explained in the example above. We test this by running deal-by-deal regressions of the loan fee level as the dependent variable, using both share and $B C$ on the right hand side.

[Table 11 about here]

The results in Table 11 are clear. In every regression share does not explain the loan fee level; by contrast, $B C$ is significant and negatively related to the loan fee levels even after controlling for share.

\subsection{A Simpler Borrower-Specific Proxy for Search Costs}

The computation of the variable $B C$ involves many steps, as presented in Section 4 . In this Section we use a simpler variable as proxy for search costs.

A short-seller calls her broker when she wants to borrow a stock. The broker then tries to locate the stock, either by searching within its inventory or by contacting lenders. If the short-seller has an account with a second broker she can access a larger portion of the lending market. A very simple borrower-specific proxy for search costs is thus the number of accounts the borrower has with different brokers. Although we do not observe this variable directly, we can estimate it by counting the number of different brokers that intermediated deals with the borrower in the entire sample. We name this variable accounts $_{k}$, where $k$ indexes the borrower. The account $s_{k}$ variable varies neither in time nor across stocks.

The average number of accounts per borrower is 1.3, the median is 1 , and the 95th percentile is 2 . Among institutions, the average is 2.4 , the median is 1 , and the 95 th percentile 
is 10. Among large borrowers, the average is 2.9, the median is 1 , and the 95th percentile is 13 . Finally, among frequent borrowers, the average is 8.2 , the median is 5 , and the 95th percentile is 26 .

Table 12 shows the estimates of the deal-by-deal panel regression of loan fee levels on the two proxies for search costs. Columns 2, 4, 6 and 8 include only account $s_{k}$ as the search cost proxy; Columns 3, 5, 7, and 9 include both proxies, accounts $s_{k}$ and $B C_{k, s, t}$. The coefficient of accounts $_{k}$ is negative and statistically significant in all regressions - even in those that also include $B C_{k, s, t}$. This constitutes additional evidence that borrower-specific search costs drive loan fees.

[Table 12 about here]

\section{Further Discussion}

As shown by many authors, short-selling constraints reduces price efficiency by excluding information from price (Asquith et al. (2005), Nagel (2005), Cao et al. (2007), Saffi and Sigurdsson (2011), Engelberg et al. (2012) and Boehmer and Wu (2013)). As was highlighted by KRR, it follows that the result that search costs affect loan fees does have important policy implications. A regulator could improve price efficiency in the stock market by reducing search costs. A natural way to reduce search costs is to reduce the opacity of the lending market. This could be done for instance via an electronic screen where lending offers are seen by all borrowers. In this Section we present preliminary evidence that a lending electronic screen reduces both loan fee levels and loan fee dispersion.

In Brazil lending transactions can occur in two ways. Most loan transactions are closed OTC (in our sample, $90 \%$ of the lending volume is OTC). Alternatively, lenders can place shares for loan directly into an online system where brokers, representing borrowers, can electronically hit the offers. ${ }^{19}$ Chague et al. (2014) use this feature of the Brazilian market to identify supply and demand shifts in the lending market and then estimate their effects on stock prices.

\footnotetext{
${ }^{19}$ Only brokers have access to this electronic screen.
} 
The more lending offers are placed on the screen, the more information the borrower has about current market conditions, and so the less opaque the lending market becomes. We measure opacity by computing for each stock-week pair the proportion $s{ }_{c r e e n}, t$ of the number of shares placed for loan on the electronic screen among the total number of shares loaned during that week. The numerator of $\operatorname{screen}_{s, t}$ measures how active the screen is during the week in terms of the quantity of loan offers. The denominator of screen $_{s, t}$ measures how

active the whole lending market is during the week. The lower $s c r e e n_{s, t}$ is, the more opaque the lending market for stock $s$ in week $t$ is.

The variable screen $_{s, t}$ significantly varies both in the cross-section and in the time-series. However, the reasons behind these variations are not clear. In what follows we directly relate loan fee level and dispersion to screen $_{s, t}$. Since the variation in screen $n_{s, t}$ might not be exogenous, we acknowledge that this exercise provides only preliminary evidence on the effect that an active lending platform could have on loan fee levels.

We regress (i) the standard deviation of loan fees within each stock-week pair on the screen $_{s, t}$ variable, (ii) the range of loan fees within each stock-week pair on the screen $_{s, t}$ variable, and (iii) the average loan fee within each stock-week pair on the $s c e_{e} n_{s, t}$ variable. We standardize the screen $_{s, t}$ variable within each firm in order to purge it of stock-specific characteristics and to allow a better interpretation of the results. As usual, we first consider all deals (from all types of borrowers) and then we restrict the sample to deals from institutions, deals from large borrowers, and deals from frequent borrowers. Table 13 presents the results.

[Table 13 about here]

Considering all deals, we find that during weeks when the number of lending offers on the screen is one standard deviation higher than the average the standard deviation of loan fees across deals is $0.057 \%$ lower, the range of loan fees is $0.441 \%$ lower, and the average loan fee is $0.193 \%$ lower, all significant at the $1 \%$ level. Considering deals only from institutions, the corresponding coefficients are $0.049 \%$ for the standard deviation, $0.394 \%$ for the range, and $0.187 \%$ for the average loan fee, all significant at the $1 \%$ level. Considering deals only from large borrowers, the coefficients are $0.054 \%$ for the standard deviation, $0.365 \%$ for the range, and $0.190 \%$ for the average loan fee, all significant at the $1 \%$ level. Finally, considering deals 
only from frequent borrowers, the coefficients are $0.049 \%$ for the standard deviation, $0.371 \%$ for the range, and $0.187 \%$ for the average loan fee, all significant at the $1 \%$ level.

These estimates indicate that an active electronic screen in the lending market can reduce both loan fee levels and loan fee dispersion. Regulators should therefore encourage the use of such platforms to reduce opacity and hence search costs in the lending market, which would increase price efficiency in the overall stock market.

\section{Concluding Remarks}

This study yields empirical evidence regarding the effects of borrower-specific search costs on equity loan fees. We introduce a measure of search cost that is based on borrowers' connections and thus views the lending market as a relationship-based market. The degree of the borrower connectedness is calculated using a unique data set that comprises all loan deals in the Brazilian market from January 2008 to July 2011. For each deal we have information on the loan quantity, the loan fee, the borrower type, the borrower ID, the broker ID, and the lender ID.

Our empirical results confirm DGP's prediction that higher search costs result in higher loan fees. These results are robust to different specifications of search costs and still hold when the sample is restricted to institutions, to large borrowers, and to frequent borrowers. Our results extend the findings by KRR that document stock-specific search costs as important determinants of loan fees.

Since higher loan fees and loan fee dispersion increase the costs and the risks of shortselling, an important policy implication is that a reduction of search costs in the lending market is very desirable. As KRR points out, this can be directly achieved by implementing a centralized trade platform. We contribute to this discussion by documenting the effect that the proportion of lending offers placed on the Brazilian electronic lending platform has on loan fees. 


\section{References}

Allen, Franklin, and Ana Babus, 2009, Networks in finance, in The Network Challenge: Strategy, Profit, and Risk in an Interlinked World, chapter 21 (Pearson Prentice Hall).

Ang, Andrew, Assaf A. Shtauber, and Paul C. Tetlock, 2013, Asset Pricing in the Dark: The Cross-Section of OTC Stocks, Review of Financial Studies 26, 2985-3028.

Asquith, Paul, Parag A. Pathak, and Jay R. Ritter, 2005, Short interest, institutional ownership, and stock returns, Journal of Financial Economics 78, 243 - 276.

Astorino, Eduardo, Fernando Chague, Bruno Cara Giovannetti, and Marcos E. Silva, 2015, Variance Premium and Implied Volatility in a Low-Liquidity Option Market, SSRN Scholarly Paper ID 2592650, Social Science Research Network, Rochester, NY.

Blocher, Jesse, Adam V. Reed, and Edward D. Van Wesep, 2013, Connecting two markets: An equilibrium framework for shorts, longs, and stock loans, Journal of Financial Economics 108, 302-322.

Boehmer, Ekkehart, and Juan (Julie) Wu, 2013, Short Selling and the Price Discovery Process, Review of Financial Studies 26, 287-322.

Cao, Bing, Dan S. Dhaliwal, Adam C. Kolasinski, and Adam V. Reed, 2007, Bears and Numbers: Investigating How Short Sellers Exploit and Affect Earnings-Based Pricing Anomalies, SSRN Scholarly Paper ID 748506, Social Science Research Network, Rochester, NY.

Chague, Fernando, Rodrigo De-Losso, Alan De Genaro, and Bruno Giovannetti, 2014, Shortsellers: Informed but restricted, Journal of International Money and Finance 47, 56-70.

Chang, Eric, Joseph W. Cheng, and Yingchui Yu, 2007, Short-Sales Constraints and Price Discovery: Evidence from the Hong Kong Market, The Journal of Finance 62, 2097-2121.

Danielsen, Bartley R., and Sorin M. Sorescu, 2001, Why Do Option Introductions Depress Stock Prices? A Study of Diminishing Short Sale Constraints, The Journal of Financial and Quantitative Analysis 36, 451-484. 
D'Avolio, Gene, 2002, The market for borrowing stock, Journal of Financial Economics 66, $271-306$.

Duffie, Darrell, Nicolae Garleanu, and Lasse Heje Pedersen, 2002, Securities lending, shorting, and pricing, Journal of Financial Economics 66, 307 - 339.

Duffie, Darrell, Nicolae Garleanu, and Lasse Heje Pedersen, 2005, Over-the-Counter Markets, Econometrica 73, 1815-1847.

Duffie, Darrell, Nicolae Garleanu, and Lasse Heje Pedersen, 2007, Valuation in Over-theCounter Markets, Review of Financial Studies 20, 1865-1900.

Duffie, Darrell, Gaston Giroux, and Gustavo Manso, 2010, Information Percolation, American Economic Journal: Microeconomics 2, 100-111.

Duffie, Darrell, Semyon Malamud, and Gustavo Manso, 2009, Information Percolation With Equilibrium Search Dynamics, Econometrica 77, 1513-1574.

Duffie, Darrell, and Gustavo Manso, 2007, Information Percolation in Large Markets, The American Economic Review 97, 203-209.

Engelberg, Joseph, Adam V. Reed, and Matthew Ringgenberg, 2013, Short Selling Risk, SSRN Scholarly Paper ID 2312625, Social Science Research Network, Rochester, NY.

Engelberg, Joseph E., Adam V. Reed, and Matthew C. Ringgenberg, 2012, How are shorts informed?: Short sellers, news, and information processing, Journal of Financial Economics $105,260-278$.

Eraker, Bjorn, and Mark Ready, 2015, Do investors overpay for stocks with lottery-like payoffs? An examination of the returns of OTC stocks, Journal of Financial Economics $115,486-504$.

Jones, Charles M., and Owen A. Lamont, 2002, Short-sale constraints and stock returns, Journal of Financial Economics 66, 207 - 239.

Kolasinski, Adam C., Adam V. Reed, and Matthew C. Ringgenberg, 2013, A Multiple Lender Approach to Understanding Supply and Search in the Equity Lending Market, The Journal of Finance 68, 559-595. 
Nagel, Stefan, 2005, Short sales, institutional investors and the cross-section of stock returns, Journal of Financial Economics 78, 277 - 309.

Newman, M., 2010, Networks: An Introduction (OUP Oxford).

Prado, Melissa Porras, 2015, Future Lending Income and Security Value, Journal of Financial and Quantitative Analysis .

Reed, Adam V., 2013, Short Selling, Annual Review of Financial Economics 5, 245-258.

Saffi, Pedro A. C., and Kari Sigurdsson, 2011, Price Efficiency and Short Selling, Review of Financial Studies 24, 821-852.

Stambaugh, Robert F., Jianfeng Yu, and Yu Yuan, 2012, The short of it: Investor sentiment and anomalies, Journal of Financial Economics 104, 288-302.

Zhu, Haoxiang, 2012, Finding a Good Price in Opaque Over-the-Counter Markets, Review of Financial Studies 25, 1255-1285. 


\section{Tables and Figures}

\section{Figure 1: Loan Fee Dispersion - Four Stocks}

This Figure shows the loan fee dispersion for the 4 stocks with the largest number of loan deals in our sample, namely, VALE5 (131,441 deals), PETR4 (107,263 deals), GGBR4 (78,916 deals) and BBDC4 (70,311). Loan fee dispersion is calculated as the standard deviation of the annualized loan fee in percentage points of all deals for the same stock on the same day. Each point in the Figure is the loan fee dispersion of a day from January 2008 to July 2011.
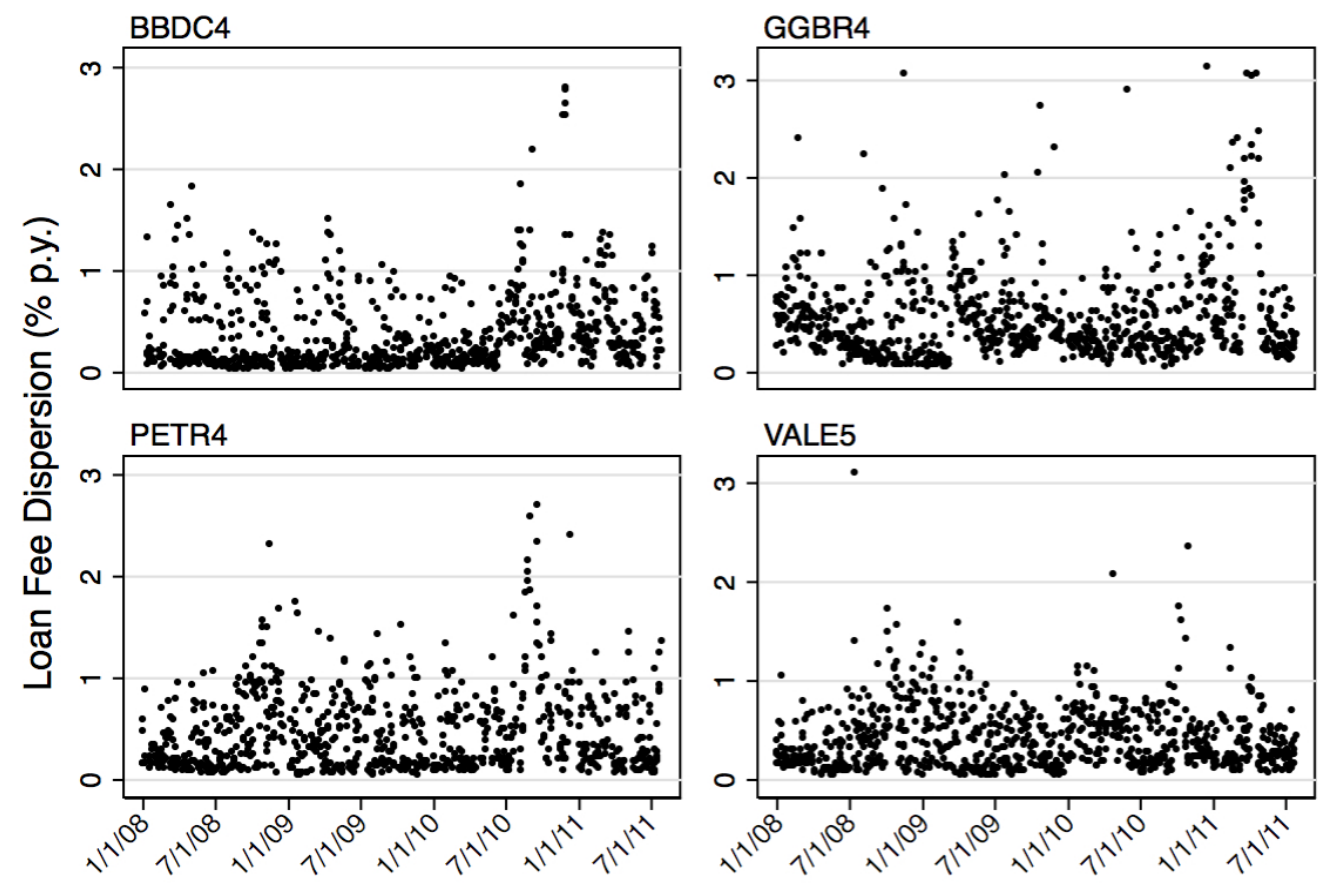


\section{Figure 2: Loan Fee Dispersion in the Cross-Section}

This Figure shows the time-series average of the loan fee dispersion for each stock in our sample. For each one of the 55 stocks in our sample we compute the average of its daily loan fee dispersion from January 2008 to July 2011. Loan fee dispersion is calculated as the standard deviation of the annualized loan fee in percentage points of all deals for the same stock on the same day. The 55 stocks are alphabetically ordered on the $\mathrm{x}$-axis.

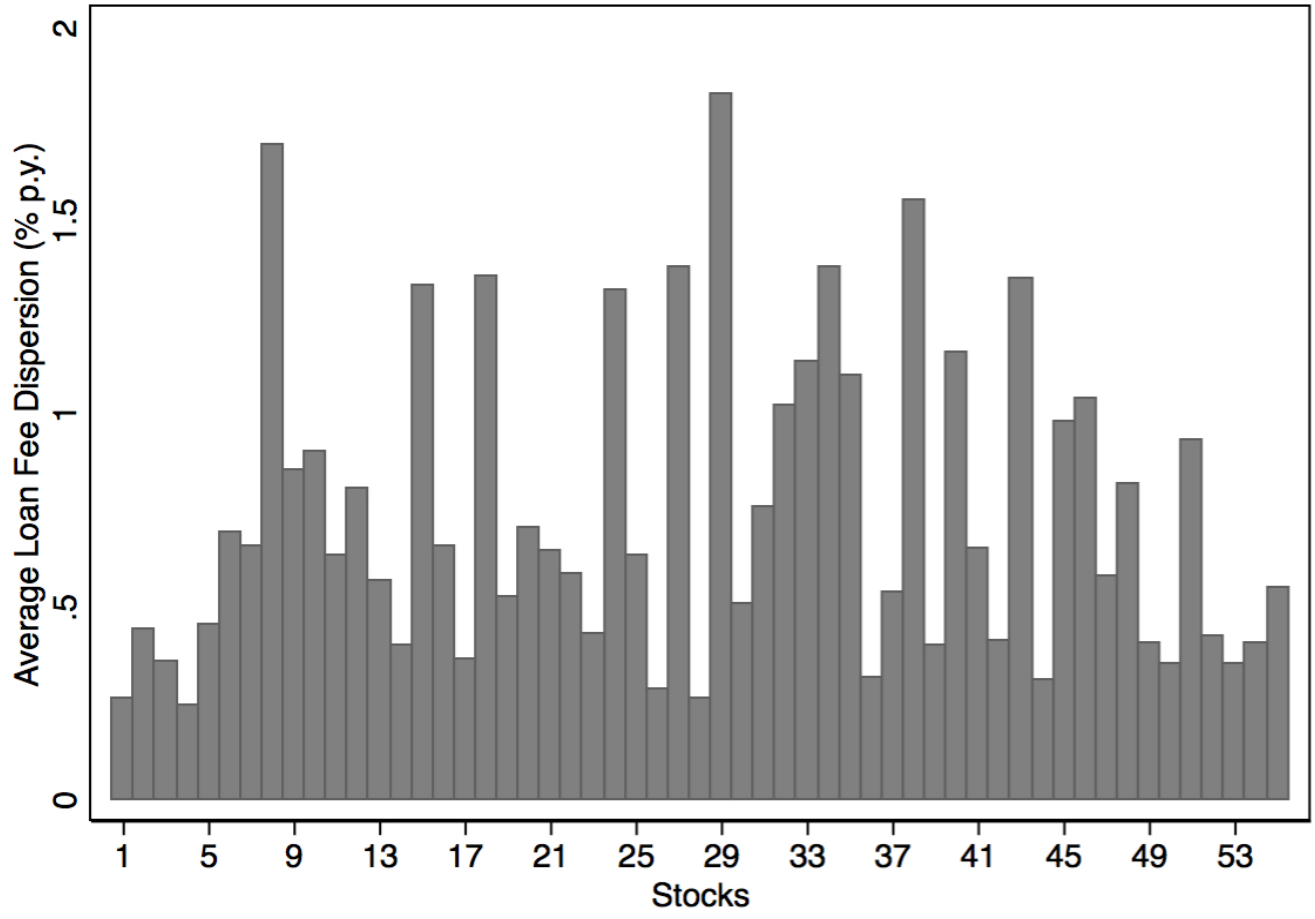




\section{Figure 3: Loan Fee Dispersion in the Time-series}

This Figure shows the cross-sectional average of the loan fee dispersion for each day in our sample. For each trading day from January 2008 to July 2011, we compute the average of the loan fee dispersion across the 55 stocks in our sample. Loan fee dispersion is calculated as the standard deviation of the annualized loan fee in percentage points of all deals for the same stock on the same day.

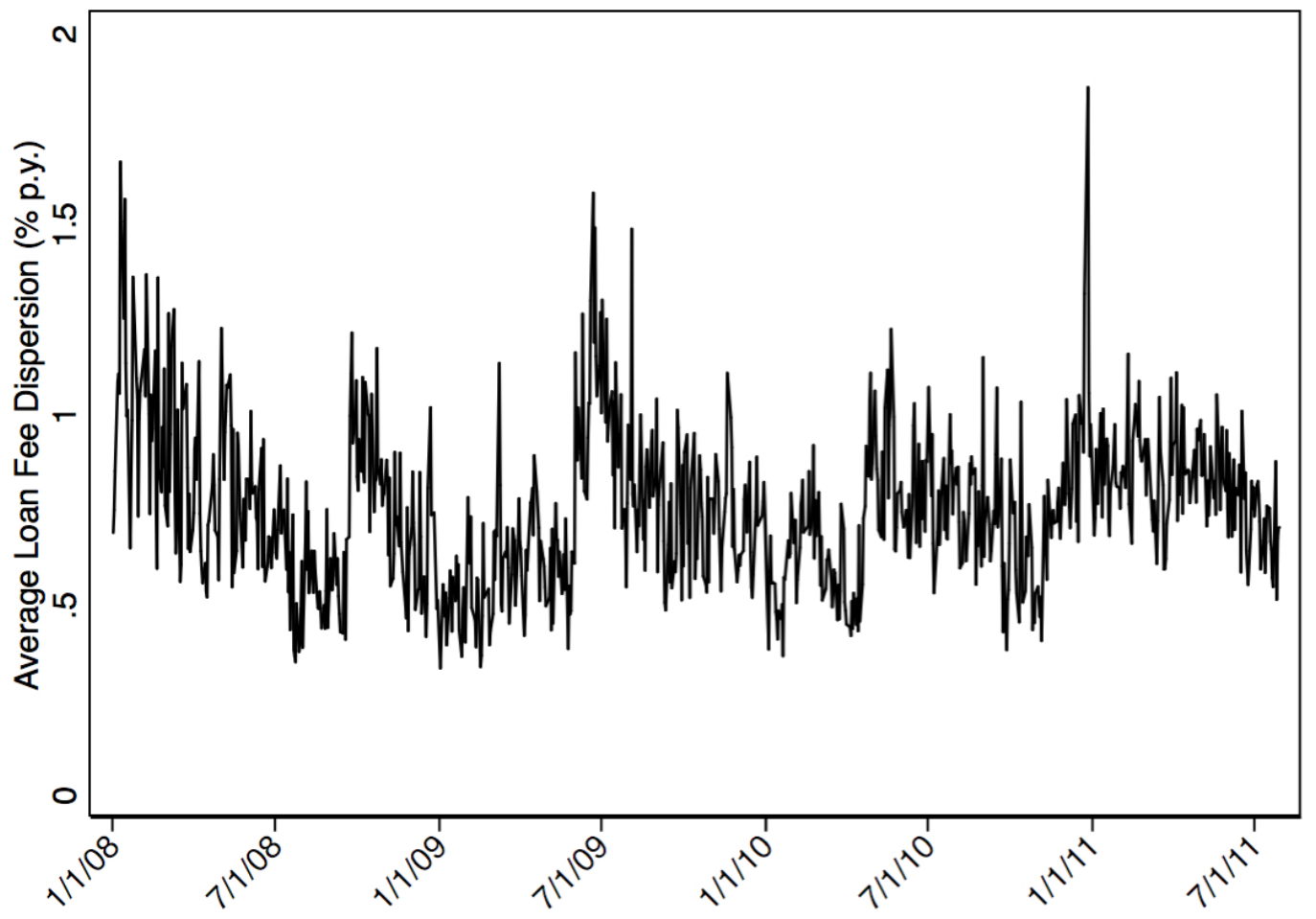




\section{Figure 4: Borrower Connection Diagram}

This Figure shows a diagram of the construction of the Borrower Connection $(B C)$ variable in a simplified lending market with three borrowers $(K=3)$, two brokers $(I=2)$ and three lenders $(J=3)$ for a given stock $s$, on a given day $t$. First we measure the importance of each lender $j$ in the lending market of

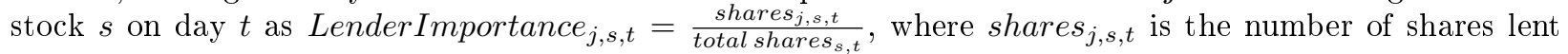
by lender $j$ of stock $s$ during the 90-day period previous to day $t$, and total shares $s_{s, t}$ is the total number of shares of stock $s$ that were loaned in the same period. We then quantify the strength of the relationship of broker $i$ with lender $j$ on day $t$ as BrokerLenderRelation ${ }_{i, j, t}=\frac{\text { deals }_{i, j, t}}{\text { totaldeals }_{j, t}}$, where deals $s_{i, j, t}$ is the total number of loan deals closed, considering all stocks, between broker $i$ and lender $j$ in the 90-day period previous to day $t$, and total deals $s_{j, t}$ is the total number of loan deals made by lender $j$ in the same period. We then compute the ability of broker $i$ to locate stock $s$ on day $t$ as BrokerReach Bis,t $=$ $\sum_{j=1}^{J}$ Lender Importance $_{j, s, t} \times$ Broker Lender Relation $_{i, j, t}$. Next, we quantify the strength of the relationship between borrower $k$ and each broker $i$ on day $t$ as BorrowerBrokerRelation $k, i, t=\frac{\text { deals }_{k, i, t}}{\text { totaldeals }_{i, t}}$, where deals $_{k, i, t}$ is the number of loan deals, considering all stock, between borrower $k$ and broker $i$ in the 90day period previous to day $t$, and total deals $s_{i, t}$ is the total number of loan deals made by broker $i$ in the same period. Finally, the connection of borrower $k$ with respect to stock $s$ on day $t$ is $B C_{k, s, t}=$ $100 \times\left(\sum_{i=1}^{I}\right.$ Broker Reach $_{i, s, t} \times$ BorrowerBrokerRelation $\left._{k, i, t}\right)$.

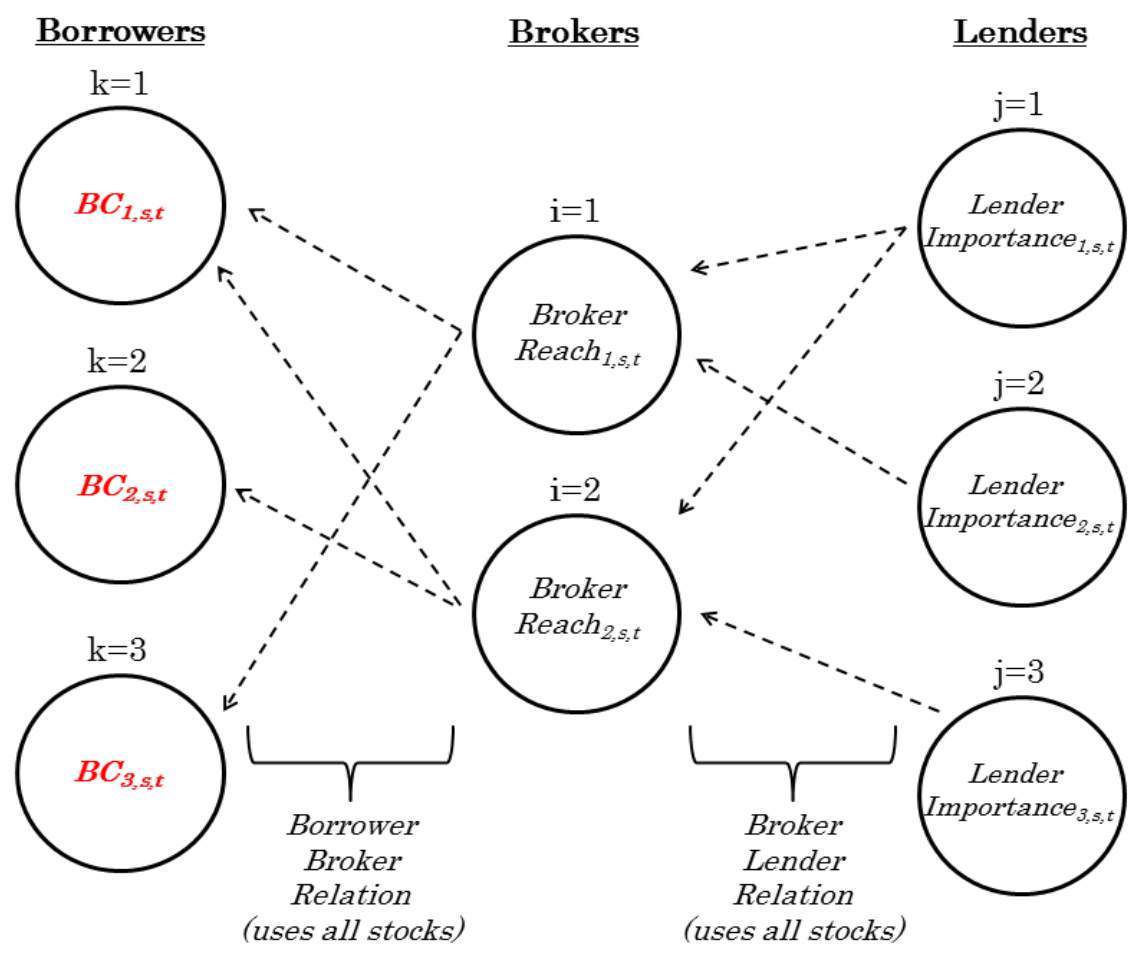




\section{Figure 5: Borrower Connection}

This Figure shows the Borrower Connection $(B C)$ variable of four arbitrary frequent borrowers on four of the most liquid stocks in the lending market: Petrobras PN (PETR4), Bradesco PN (BBDC4), Gerdau PN (GGBR4) and Vale do Rio Doce PN (VALE5). The calculation of the variable $B C$ is described in Section 4. $B C$ is a time-varying (at the daily frequency) and stock-specific variable which it is decreasing in the borrower's search costs. A high value here means that the borrower has strong relationships with brokers which in turn have strong relationships with important lenders of the stock. The sample period is from July of 2008 to July 2011, and the frequency is daily.

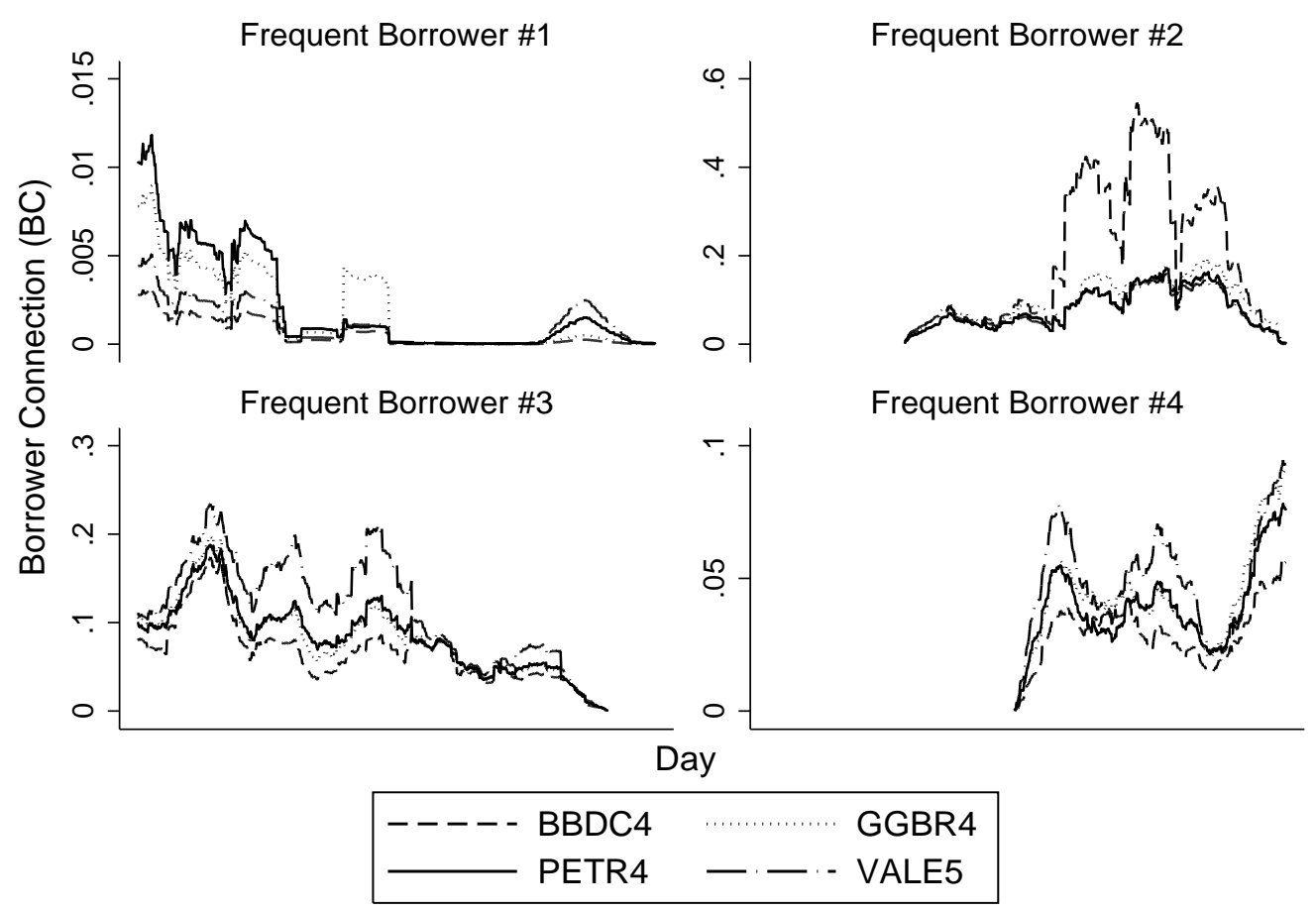




\section{Figure 6: Level Fixed Effect vs. Dispersion Fixed Effect}

This Figure shows the scatter-plot between the level fixed effect and the dispersion fixed effect of each one of the 55 stocks in our sample. The level fixed effect is the stock fixed effect estimated in Table 5. The dispersion fixed effect is the stock fixed effect estimated in Table 6.

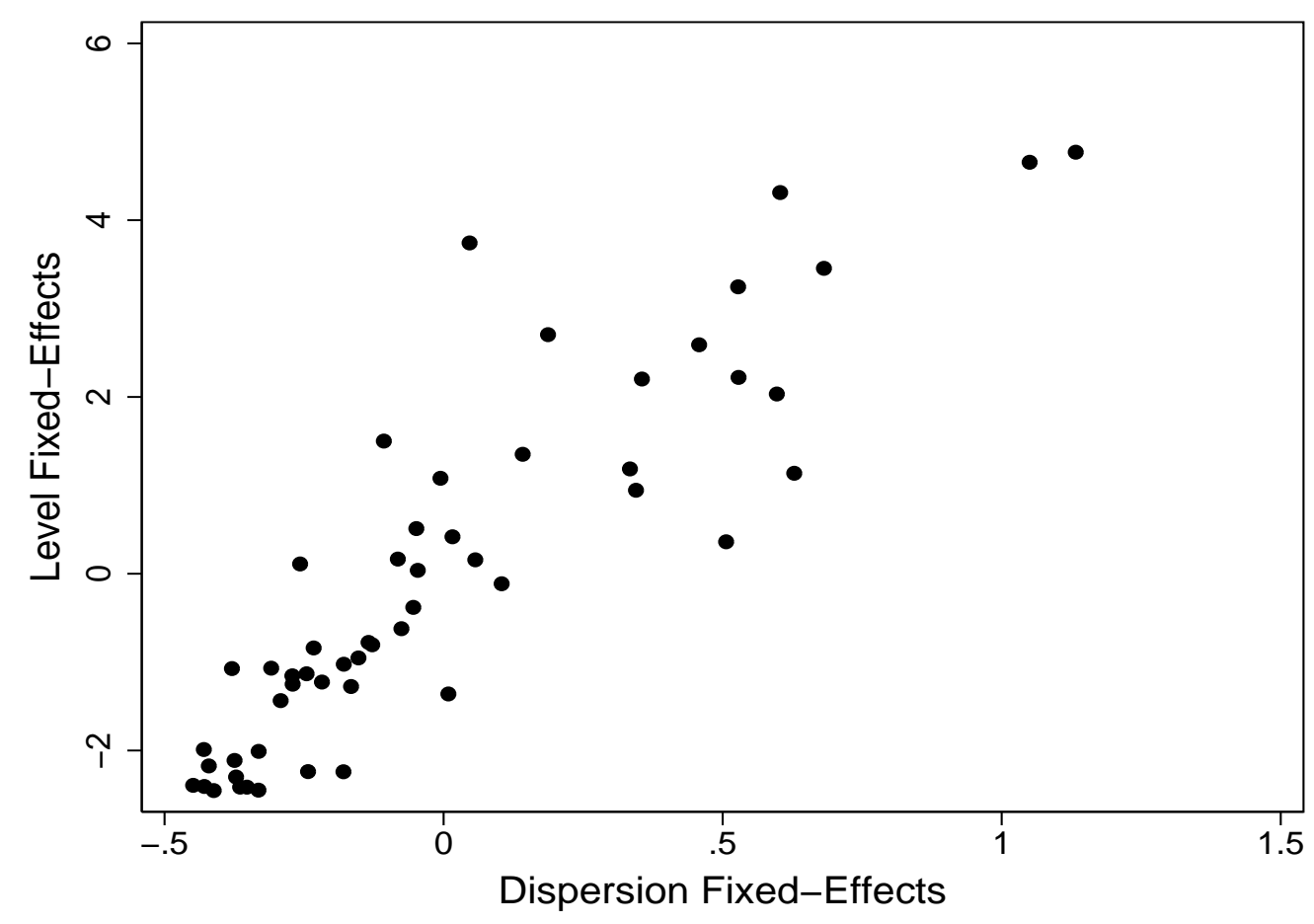




\section{Figure 7: Number of Loan Deals by Brokers}

This Figure shows the number of lending deals intermediated by each broker during January 2008 and July 2011. The 91 brokers are sorted on the x-axis according to the total number of deals.

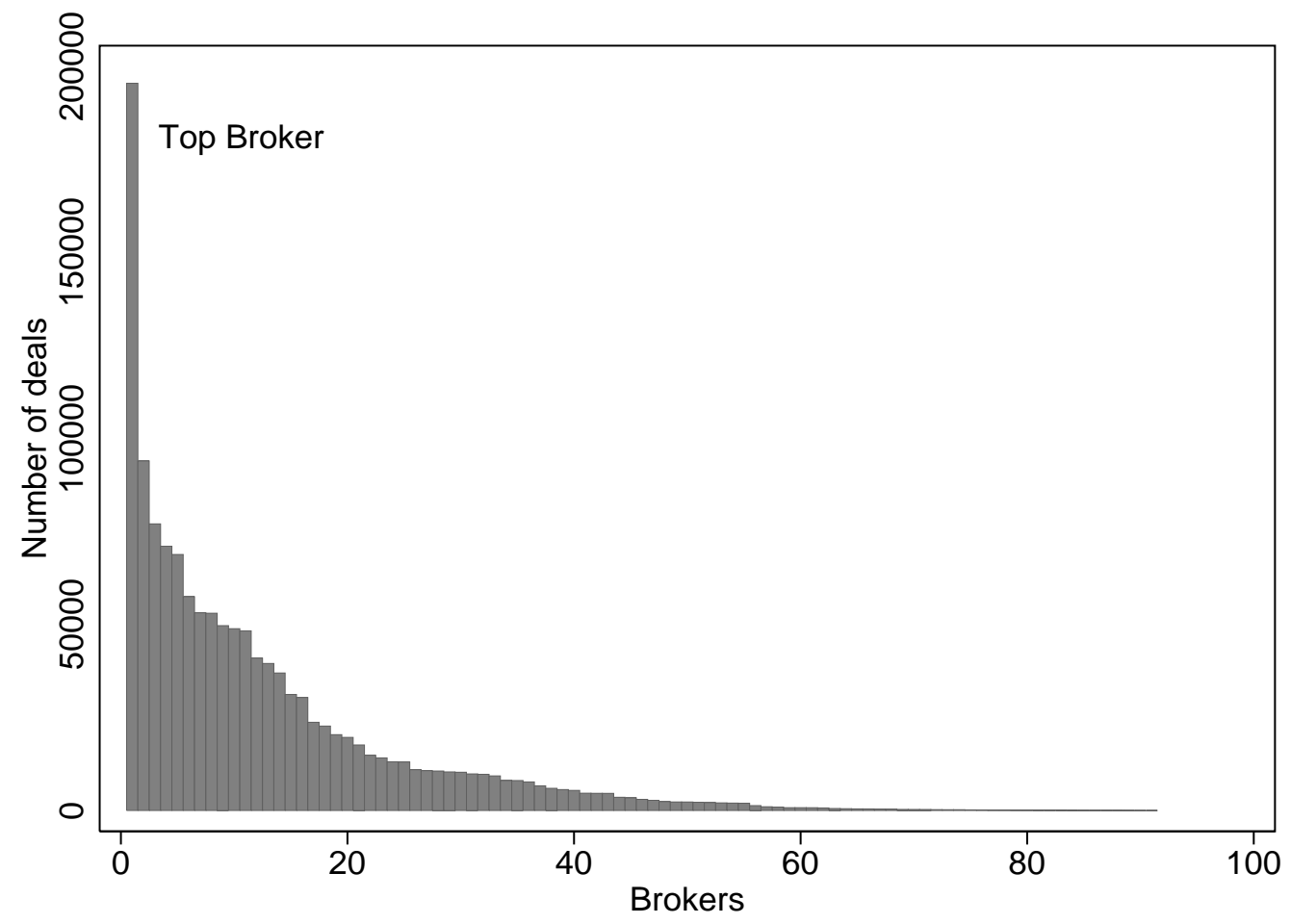




\section{Figure 8: Inside the Top Broker: Loan Fee Dispersion in the Cross-section}

This Figure shows the time-series average of the loan fee dispersion inside the top broker for each stock in our sample. For each one of the 55 stocks in our sample, we compute the average of its daily loan fee dispersion from January 2008 to July 2011. Loan fee dispersion is calculated as the standard deviation of the annualized loan fee in percentage points of all deals intermediated by the top broker for the same stock on the same day. The 55 stocks are alphabetically ordered on the $\mathrm{x}$-axis. The top broker is the broker with the highest number of closed deals in the entire sample.

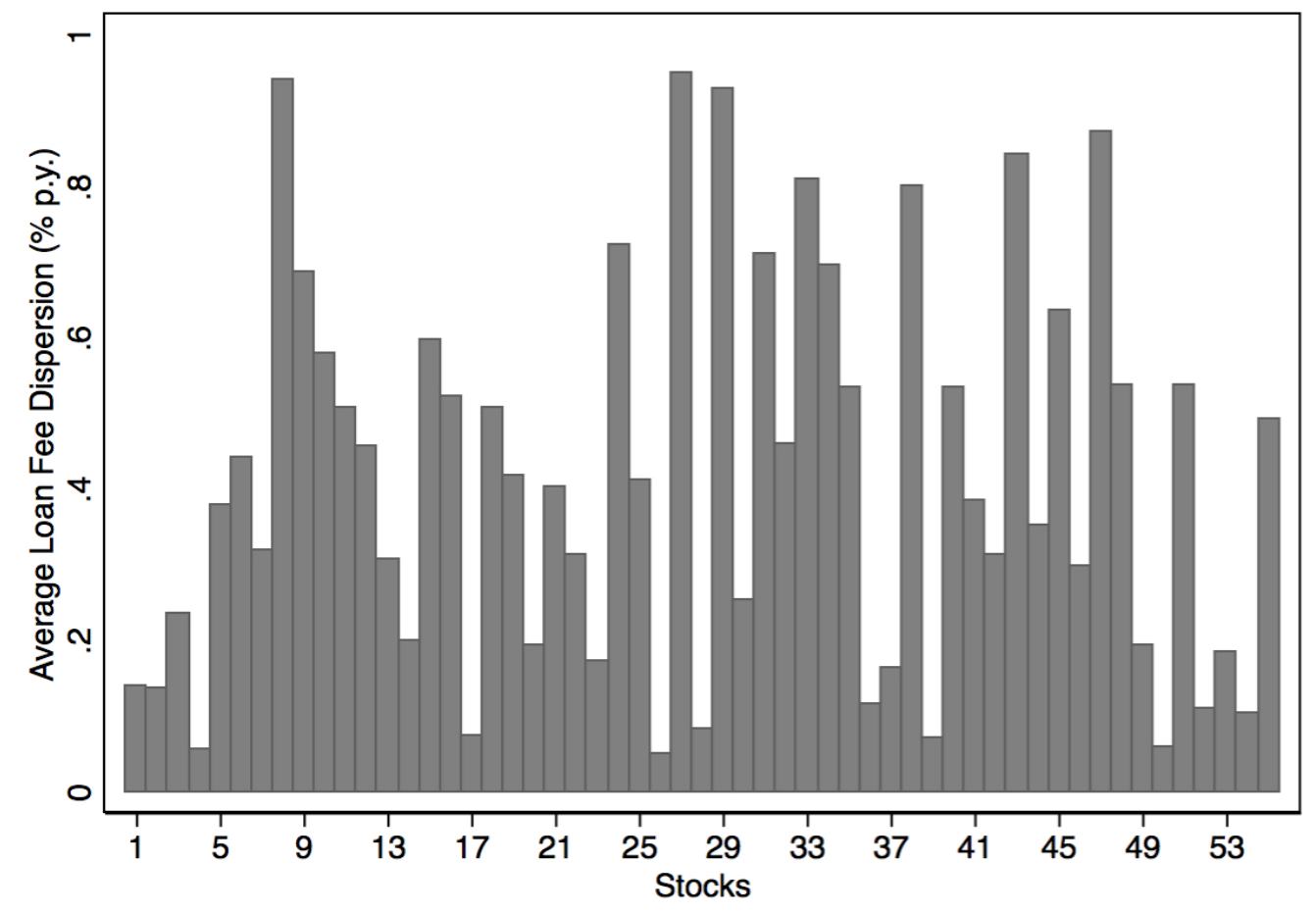


Figure 9: Inside the Top Broker: Loan Fee Dispersion in the Time-series

This Figure shows the cross-sectional average of the loan fee dispersion inside the top broker for each day in our sample. For each trading day from January 2008 to July 2011, we compute the average of the loan fee dispersion across the 55 stocks in our sample. Loan fee dispersion is calculated as the standard deviation of the annualized loan fee in percentage points of all deals intermediated by the top broker for the same stock on the same day. The top broker is the broker with the highest number of deals closed in the entire sample.

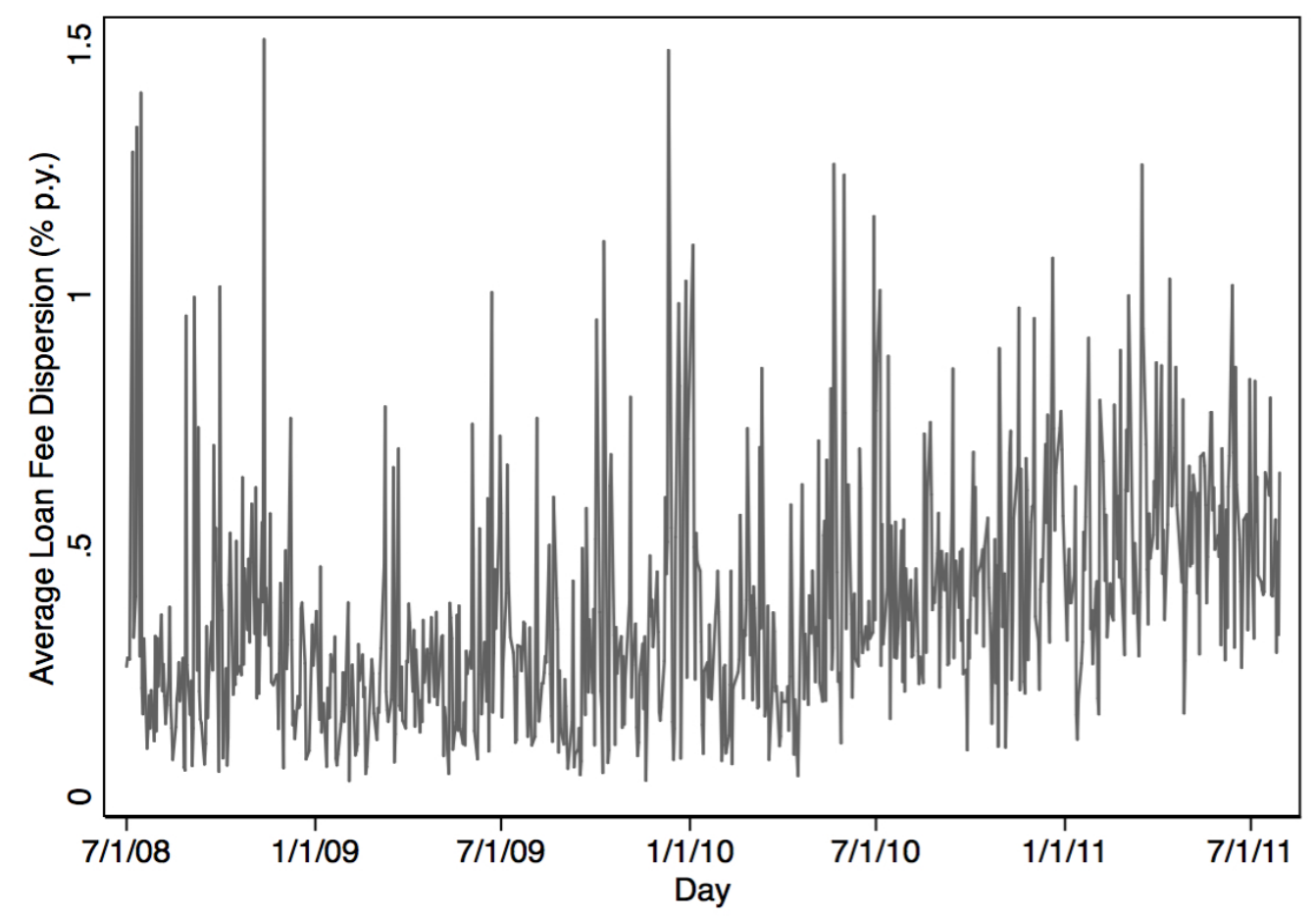




\section{Table 1: Number of Borrowers and Lenders by Year}

This Table shows the number of different borrowers and lenders in the lending market per year. The data set identifies each investor with a unique ID. An investor who closed both a borrowing and a lending deal in the same year is included in both columns. The last line considers only the first 7 months of 2011 .

\begin{tabular}{ccc} 
Year & \# of Borrowers & \# of Lenders \\
\hline 2008 & 17,435 & 3,471 \\
2009 & 22,166 & 3,416 \\
2010 & 24,809 & 6,785 \\
2011 (Jan-Jul) & 16,515 & 8,103 \\
\hline \hline
\end{tabular}




\section{Table 2: Descriptive Statistics by Stock}

This Table reports, stock by stock, the stock ticker, the average Loan Fee Dispersion (LFD), the standard deviation of the LFD, the daily average number of loan deals, and the average loan fee (\% per year). We measure LFD as the standard deviation of the annualized loan fee of all deals for the same stock on a given day.

\begin{tabular}{|c|c|c|c|c|}
\hline \multirow{2}{*}{ Ticker } & \multicolumn{2}{|c|}{ Loan Fee Dispersion } & \multicolumn{2}{|c|}{ Loan Deals } \\
\hline & Avg. & Std. Dev. & Per Day & Fee (in \%) \\
\hline AMBV4 & 0.32 & 0.58 & 58 & 0.65 \\
\hline BBAS3 & 0.61 & 1.24 & 80 & 1.04 \\
\hline $\mathrm{BBDC} 4$ & 0.43 & 0.43 & 113 & 0.54 \\
\hline BRAP4 & 0.25 & 0.33 & 26 & 0.74 \\
\hline BRKM5 & 0.55 & 0.45 & 49 & 1.88 \\
\hline BRML3 & 0.62 & 0.77 & 27 & 5.18 \\
\hline BRTO4 & 0.88 & 2.02 & 24 & 2.36 \\
\hline BTOW3 & 1.77 & 1.88 & 33 & 5.16 \\
\hline CCRO3 & 0.90 & 1.17 & 31 & 3.33 \\
\hline CESP6 & 0.91 & 0.80 & 25 & 1.72 \\
\hline CMIG4 & 0.69 & 0.58 & 66 & 2.07 \\
\hline CPFE3 & 0.86 & 0.61 & 48 & 4.82 \\
\hline CPLE6 & 0.60 & 0.49 & 29 & 2.20 \\
\hline CRUZ3 & 0.42 & 0.39 & 61 & 2.12 \\
\hline CSAN3 & 1.26 & 1.73 & 33 & 5.34 \\
\hline CSMG3 & 0.62 & 1.19 & 8 & 3.49 \\
\hline CSNA3 & 0.36 & 0.38 & 91 & 0.86 \\
\hline CYRE3 & 1.32 & 1.54 & 56 & 6.03 \\
\hline ELET3 & 0.62 & 0.84 & 22 & 1.90 \\
\hline ELET6 & 0.78 & 1.20 & 58 & 4.32 \\
\hline EMBR3 & 0.65 & 0.89 & 33 & 2.46 \\
\hline ENBR3 & 0.71 & 1.11 & 19 & 4.41 \\
\hline FFTL4 & 0.59 & 0.76 & 15 & 1.80 \\
\hline GFSA3 & 1.29 & 1.26 & 45 & 6.17 \\
\hline GGBR4 & 0.71 & 0.88 & 118 & 2.19 \\
\hline GOAU4 & 0.29 & 0.66 & 26 & 0.52 \\
\hline GOLL4 & 1.46 & 1.20 & 31 & 4.87 \\
\hline ITSA4 & 0.26 & 0.38 & 55 & 0.41 \\
\hline JBSS3 & 1.97 & 1.83 & 48 & 8.20 \\
\hline KLBN4 & 0.53 & 0.88 & 54 & 2.67 \\
\hline LAME4 & 0.80 & 0.76 & 66 & 3.28 \\
\hline LIGT3 & 0.99 & 1.32 & 42 & 4.64 \\
\hline LREN3 & 1.28 & 0.89 & 51 & 6.15 \\
\hline MRVE3 & 1.40 & 1.9342 & 56 & 6.92 \\
\hline NATU3 & 1.06 & 0.97 & 67 & 6.25 \\
\hline
\end{tabular}


(continues from previous page).

\begin{tabular}{lcccc}
\multirow{2}{*}{ Ticker } & \multicolumn{2}{c}{ Loan Fee Dispersion } & \multicolumn{2}{c}{ Loan Deals } \\
& Avg. & Std. Dev. & Per Day & Fee (in \%) \\
\hline PETR3 & 0.36 & 0.92 & 62 & 0.70 \\
PETR4 & 0.62 & 0.95 & 154 & 0.77 \\
RDCD3 & 1.49 & 1.62 & 71 & 7.20 \\
RENT3 & 0.35 & 0.49 & 28 & 3.58 \\
RSID3 & 1.13 & 1.40 & 44 & 4.87 \\
SBSP3 & 0.83 & 1.24 & 22 & 2.50 \\
SUZB5 & 0.50 & 0.49 & 22 & 2.38 \\
TAMM4 & 1.38 & 1.28 & 29 & 3.57 \\
TBLE3 & 0.40 & 0.38 & 26 & 2.13 \\
TCSL4 & 1.11 & 1.21 & 44 & 5.24 \\
TMAR5 & 1.14 & 1.32 & 19 & 4.38 \\
TNLP3 & 0.56 & 0.73 & 12 & 2.25 \\
TNLP4 & 0.87 & 0.73 & 59 & 3.42 \\
TRPL4 & 0.44 & 0.50 & 19 & 1.81 \\
UGPA4 & 0.33 & 0.88 & 25 & 1.05 \\
USIM3 & 1.40 & 1.67 & 32 & 5.13 \\
USIM5 & 0.44 & 0.37 & 92 & 1.26 \\
VALE3 & 0.40 & 0.41 & 77 & 0.64 \\
VALE5 & 0.42 & 0.33 & 169 & 0.47 \\
WEGE3 & 0.76 & 0.80 & 23 & 3.76 \\
\hline \hline
\end{tabular}




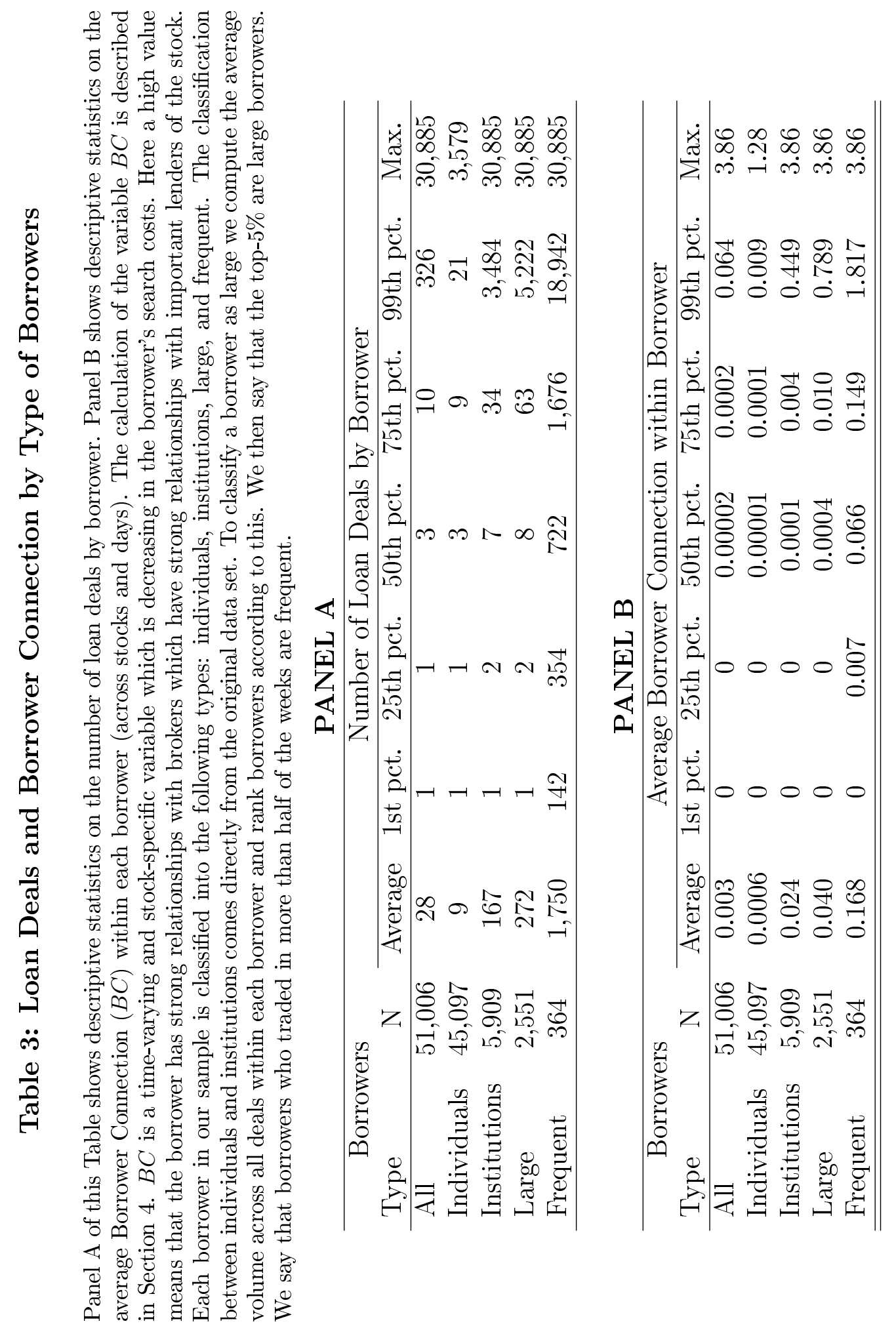




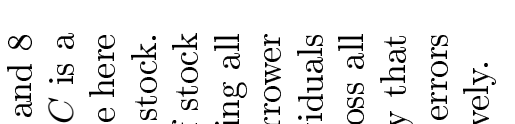

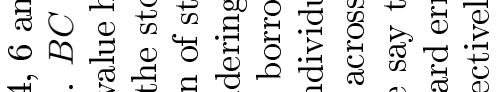
オ+ त

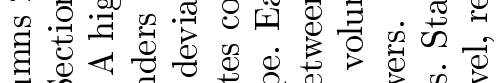

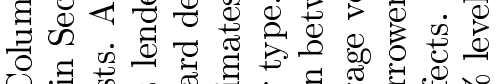
ర․․

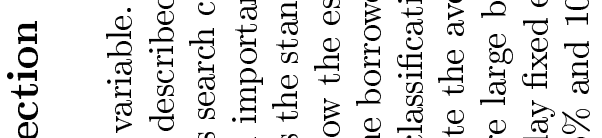

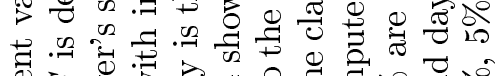

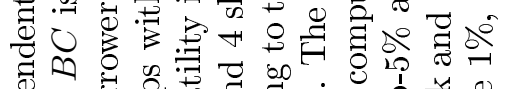

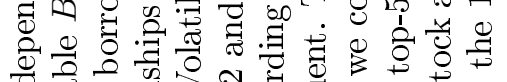

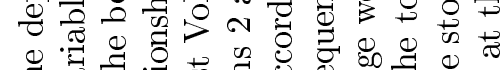

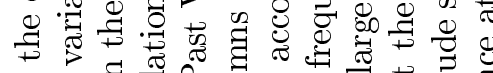

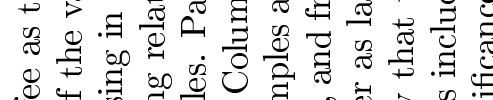

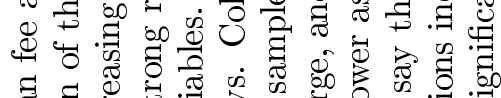

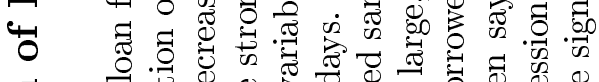

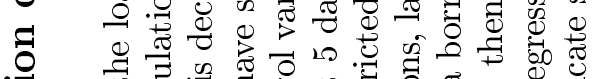

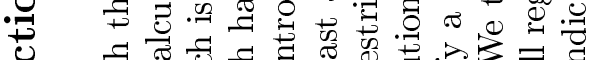

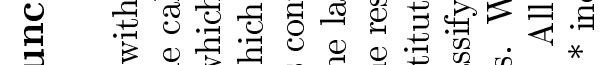

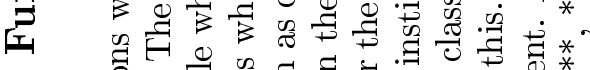

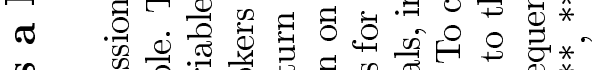

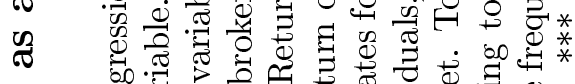

D

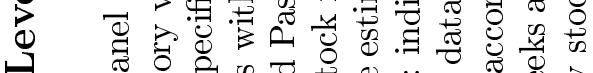

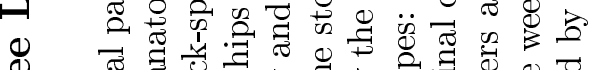

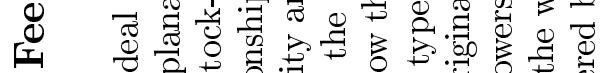

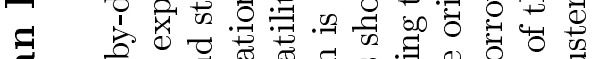

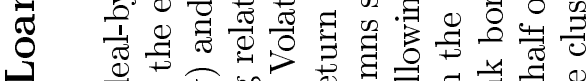

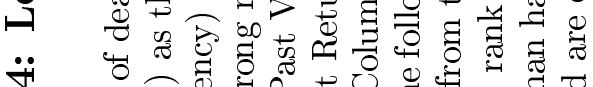

$\ddot{\forall}$ कठ

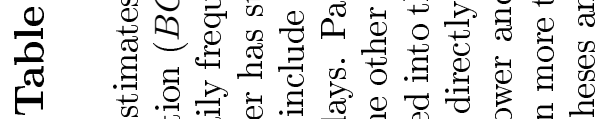

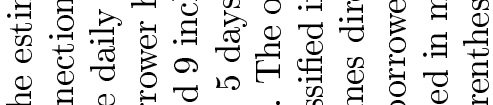

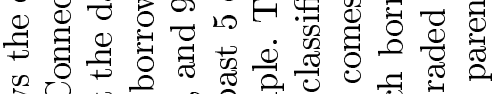

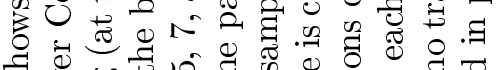

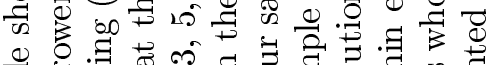

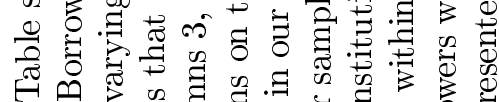

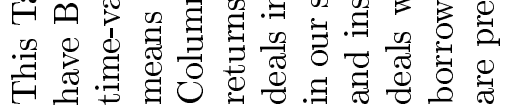

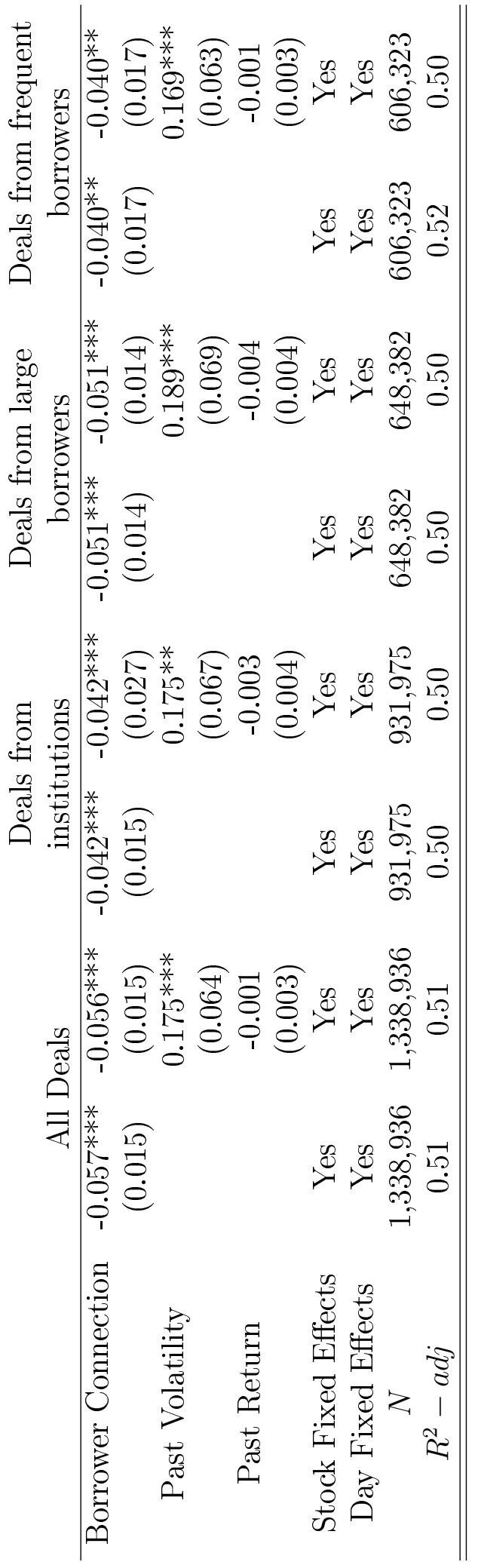




\section{Table 5: Loan Fee Level for High-, Medium- and Low-connected Borrowers}

This Table presents estimates of nonlinear effects of $B C$ on the loan fee. Within each stock-week pair, we rank deals with respect to the borrowers' $B C$ and classify them into three groups: low- $B C$ group if $B C$ falls below the $50 \%$-percentile, medium- $B C$ group if it falls between the $50 \%$ - and the $90 \%$-percentile, and high- $B C$ group if it falls above the $90 \%$-percentile. For each stock-week-group cell we compute the average loan fee across all deals. We then run panel regressions of this average loan fee on two dummy variables, High and Low. High takes value one if the cell refers to the high- $B C$ group and zero otherwise. Low takes value one if the cell refers to the low- $B C$ and zero otherwise. $B C$ is a time-varying and stock-specific variable which is decreasing in the borrower's search costs. The calculation of the variable $B C$ is described in Section 4. Column 2 in the Table shows the estimates considering all deals in our sample. Columns 3, 4, and 5 consider deals from samples restricted according to borrowers type: institutional, large and frequent. Classification between individuals and institutions comes directly from the original data set. To classify a borrower as large we compute the average volume across all deals within each borrower and rank borrowers according to this. We then say that the top- $5 \%$ are large borrowers. We say that borrowers who traded in more than half of the weeks are frequent. All regressions include stock and week fixed effects. Standard errors are presented in parentheses and are clustered by stock. $* * *, * *, *$ indicate significance at the $1 \%, 5 \%$ and $10 \%$ level, respectively.

\begin{tabular}{ccccc} 
& All Borrowers & Institutions & Large & Frequent \\
\hline High & $-0.153^{* * *}$ & $-0.157^{* * *}$ & $-0.189^{* * *}$ & $-0.213^{* * *}$ \\
& $(0.028)$ & $(0.029)$ & $(0.037)$ & $(0.038)$ \\
Low & $0.186^{* * *}$ & $0.060^{* * *}$ & $0.055^{* *}$ & $0.066^{* * *}$ \\
& $(0.026)$ & $(0.020)$ & $(0.023)$ & $(0.024)$ \\
Stock Fixed Effects & Yes & Yes & Yes & Yes \\
Week Fixed Effects & Yes & Yes & Yes & Yes \\
$N$ & 25,323 & 25,149 & 24,474 & 24,558 \\
$R^{2}-a d j$ & 0.53 & 0.52 & 0.51 & 0.51 \\
\hline \hline
\end{tabular}



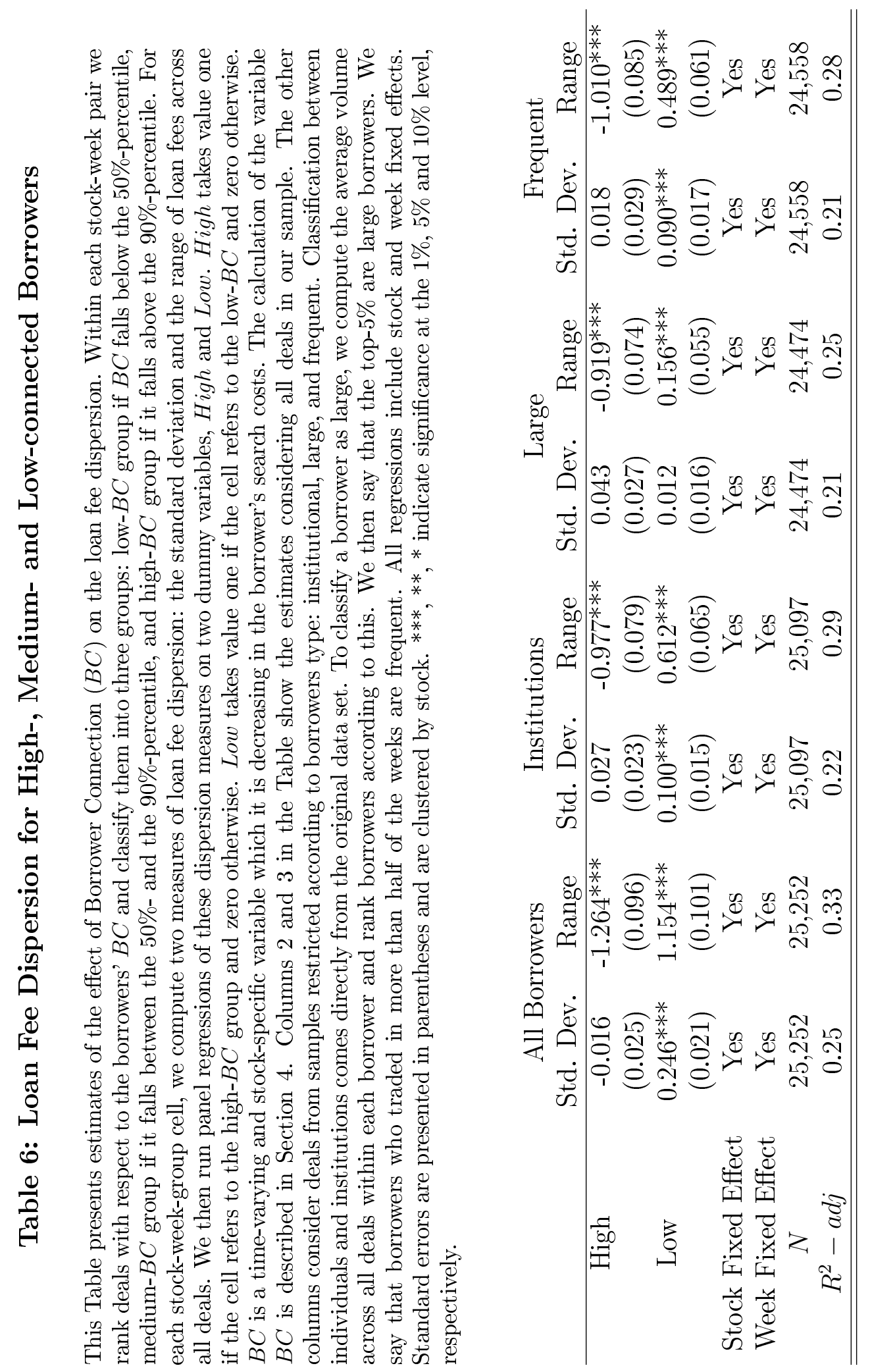


\section{Table 7: Brokerage Fee and Borrowers Connection}

Panel A of this Table shows the estimates of deal-by-deal panel regressions of brokerage fee on Borrower Connection $(B C)$. Brokerage fee is the fee in \% p.y. paid by borrower in the loan deal. $B C$ is a time-varying and stock-specific variable which is decreasing in the borrower's search costs. The calculation of the variable $B C$ is described in Section 4. Panel B presents estimates of nonlinear effects of $B C$ on brokerage fee. Within each stock-week pair we rank deals with respect to the borrowers $B C$ and classify them into three groups: low- $B C$ group if $B C$ falls below the $50 \%$-percentile, medium- $B C$ group if it falls between the $50 \%$ - and the $90 \%$-percentile, and high- $B C$ group if it falls above the $90 \%$-percentile. For each stock-week-group cell we compute the average brokerage fee across all deals. We then run panel regressions of this average brokerage fee on two dummy variables, High and Low. High takes value one if the cell refers to the high-BC group and zero otherwise. Low takes value one if the cell refers to the low- $B C$ and zero otherwise. Column 2 of both Panels shows the estimates considering all deals in our sample. Columns 3,4 , and 5 consider deals from samples restricted according to borrowers type: institutional, large, and frequent. Classification between individuals and institutions comes directly from the original data set. To classify a borrower as large, we do the following. We compute the average volume across all deals within each borrower and rank borrowers according to this. We then say that the top- $5 \%$ are large borrowers. We say that borrowers that traded in more than half of the weeks are frequent. All regressions include stock and time fixed effects. Standard errors are presented in parentheses and are clustered by stock. $* * *, * *, *$ indicate significance at the $1 \%, 5 \%$ and $10 \%$ level, respectively.

PANEL A

Deals from Deals from large Deals from frequent

\begin{tabular}{ccccc} 
& All deals & institutions & borrowers & borrowers \\
\hline Borrower Connection & $-0.042^{* * *}$ & $-0.013^{* * *}$ & $-0.010^{* * *}$ & $-0.012^{* * *}$ \\
& $(0.005)$ & $(0.002)$ & $(0.002)$ & $(0.002)$ \\
Stock Fixed Effect & Yes & Yes & Yes & Yes \\
Day Fixed Effect & Yes & Yes & Yes & Yes \\
$N$ & $1,339,089$ & 932,081 & 648,496 & 606,427 \\
$R^{2}-$ adj & 0.024 & 0.022 & 0.022 & 0.026 \\
\hline
\end{tabular}

\section{PANEL B}

\begin{tabular}{ccccc} 
& All deals & $\begin{array}{c}\text { Deals from } \\
\text { institutions }\end{array}$ & $\begin{array}{c}\text { Deals from large } \\
\text { borrowers }\end{array}$ & $\begin{array}{c}\text { Deals from frequent } \\
\text { borrowers }\end{array}$ \\
\hline High & $-0.034^{* * *}$ & $-0.017^{* * *}$ & $-0.018^{* * *}$ & $-0.023^{* * *}$ \\
& $(0.005)$ & $(0.005)$ & $(0.005)$ & $(0.005)$ \\
Low & $0.158^{* * *}$ & $0.050^{* * *}$ & $0.030^{* * *}$ & $0.052^{* * *}$ \\
& $(0.006)$ & $(0.005)$ & $(0.004)$ & $(0.005)$ \\
Stock Fixed Effect & Yes & Yes & Yes & Yes \\
Week Fixed Effect & Yes & Yes & Yes & Yes \\
$N$ & 25,258 & 25,103 & 24,479 & 24,562 \\
$R^{2}-a d j$ & 0.187 & 0.084 & 0.078 & 0.080 \\
\hline \hline
\end{tabular}




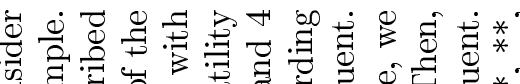
वै द्वृ

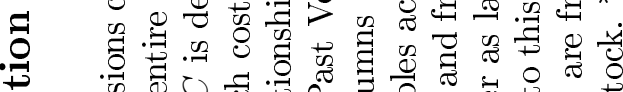

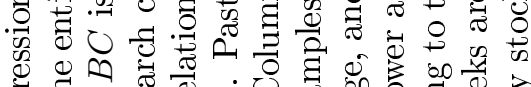

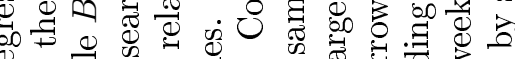

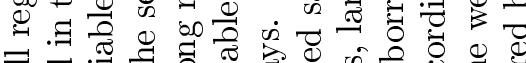

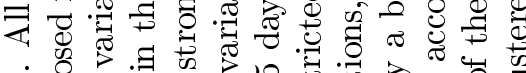

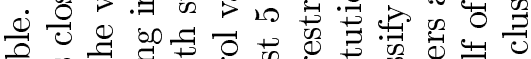

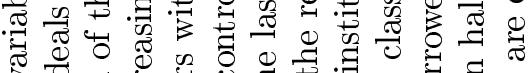
$>$ च

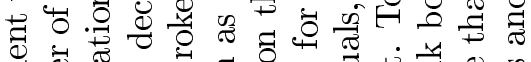
过

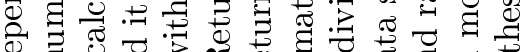
\%

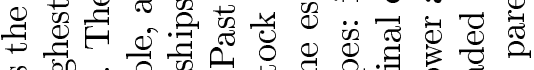

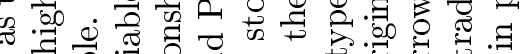
\& สี

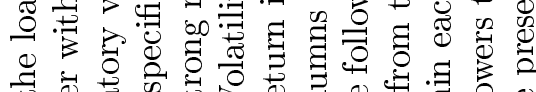

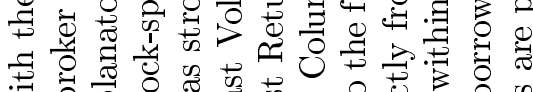

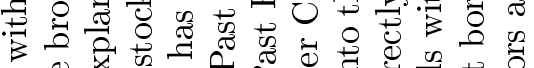

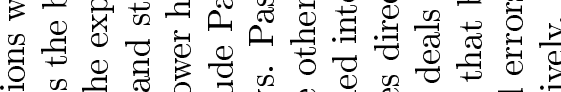

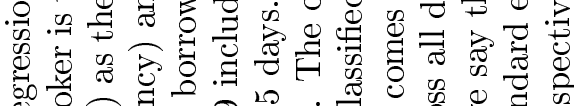

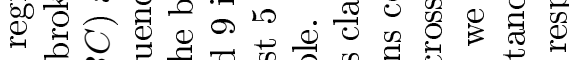

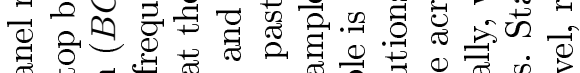

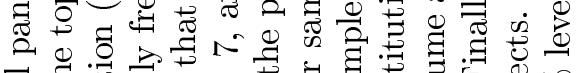

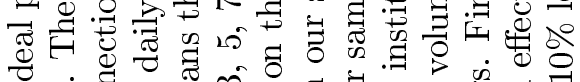

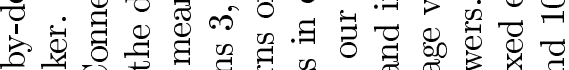

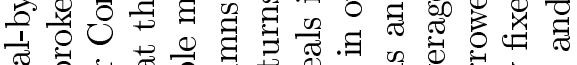

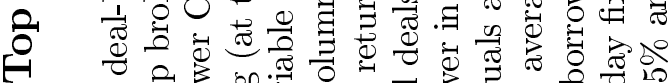
फ

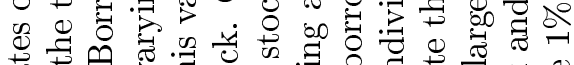

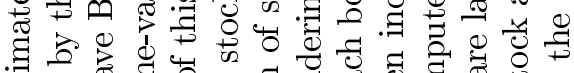

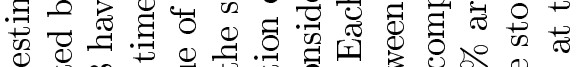

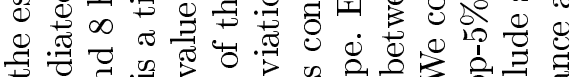

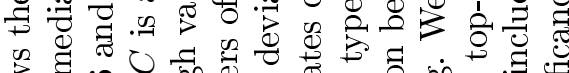
它 $\begin{aligned} & \sigma \\ & 0\end{aligned}$

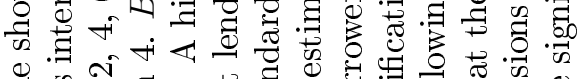

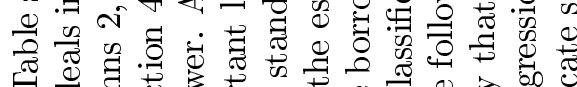

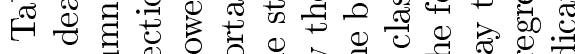
↔

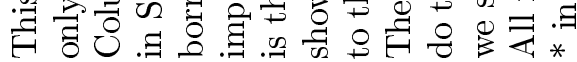

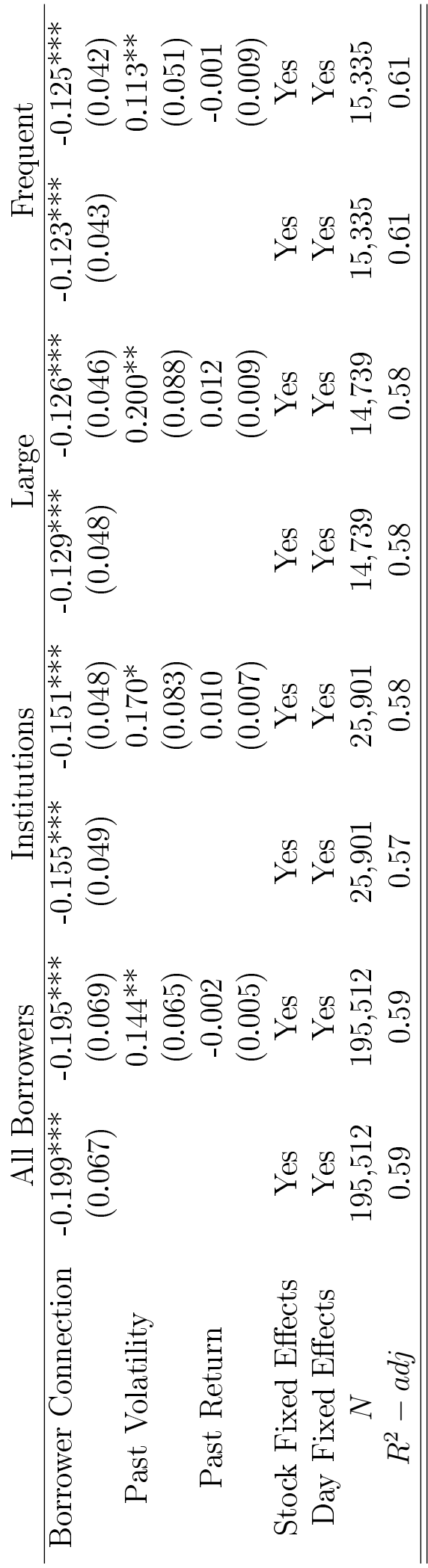




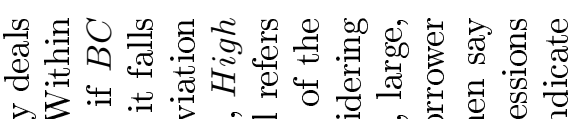

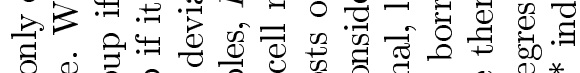

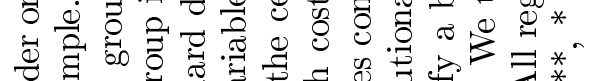

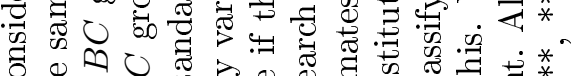

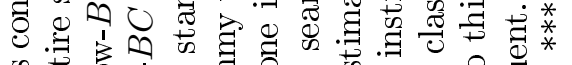

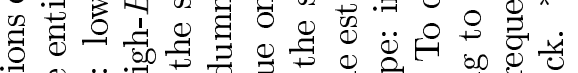

ช్

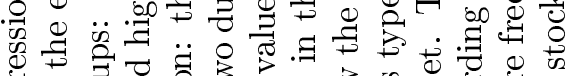

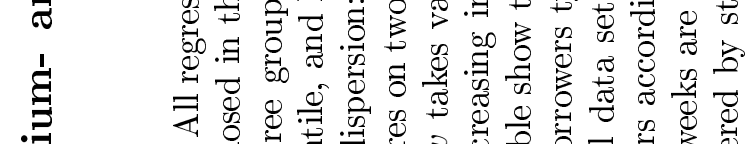

可 य

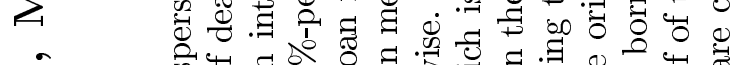

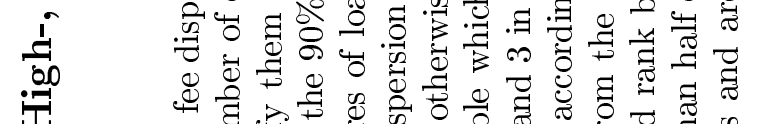

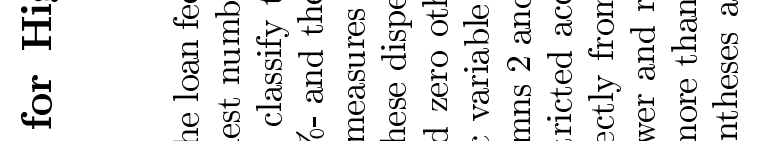

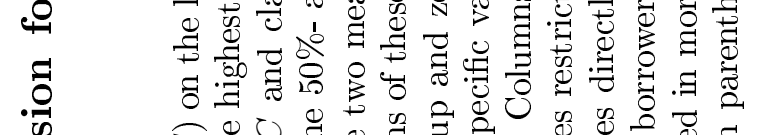

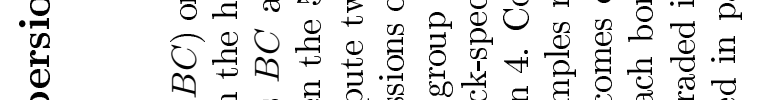

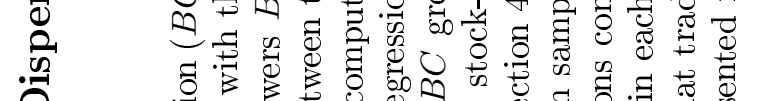

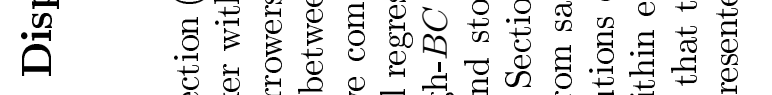

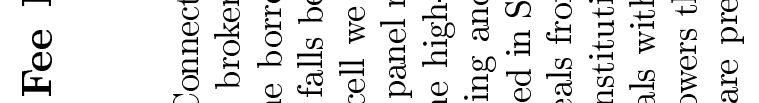

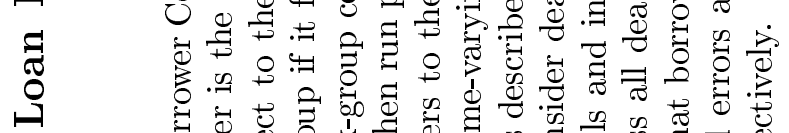

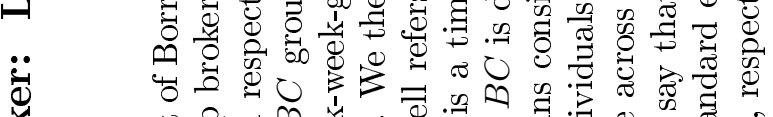

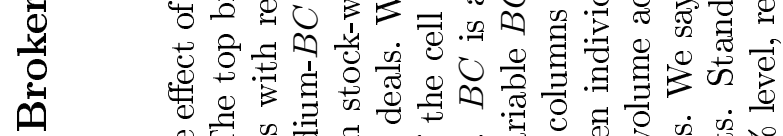

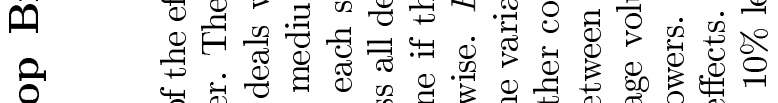

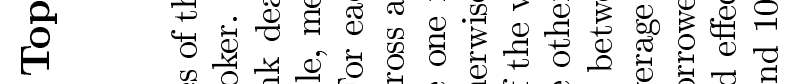

ڤ

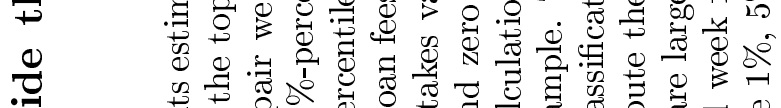

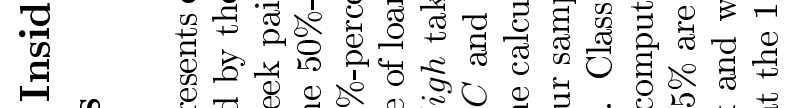

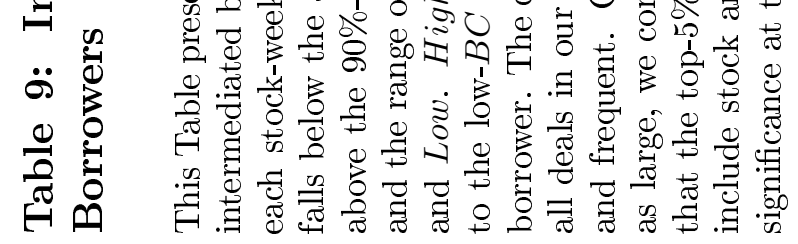

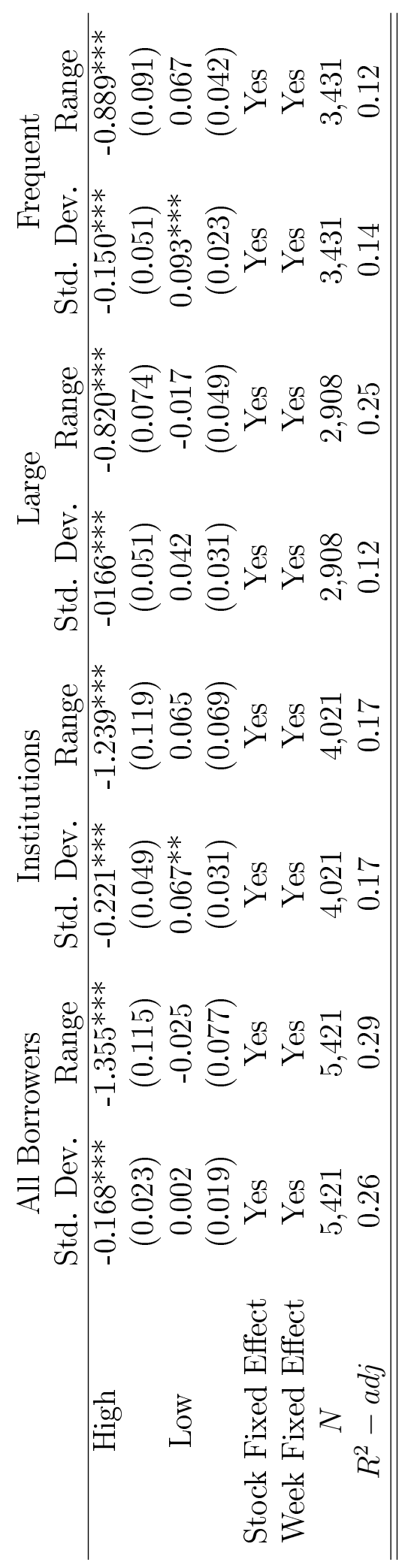




\section{Table 10: Borrower Connection vs. Borrower Market Share}

This Table shows deal-by-deal panel regressions of borrower market share (share) on Borrower Connection $(B C)$. share is the lending market share of borrower $k$ with respect to stock $s$ in the 90-day window previous to day $t$. It is calculated as the ratio between the quantity borrowed by $k$ and total quantity borrowed in the market. $B C$ is also a time-varying and stock-specific variable which is decreasing in the borrower's search costs. The calculation of the variable $B C$ is described in Section 4. Column 2 shows the estimates considering all deals in our sample. Columns 3,4 , and 5 consider deals from samples restricted according to borrowers type: institutional, large and frequent. Classification between individuals and institutions comes directly from the original data set. To classify a borrower as large we compute the average volume across all deals within each borrower and rank borrowers according to this. We then say that the top-5\% are large

borrowers. We say that borrowers that traded in more than half of the weeks are frequent. Standard errors are presented in parentheses and are clustered by stock. ${ }^{* * *}, * *, *$ indicate significance at the $1 \%, 5 \%$, and $10 \%$ level, respectively.

\begin{tabular}{ccccc} 
& All deals & $\begin{array}{c}\text { Deals from } \\
\text { institutions }\end{array}$ & $\begin{array}{c}\text { Deals from large } \\
\text { borrowers }\end{array}$ & $\begin{array}{c}\text { Deals from frequent } \\
\text { borrowers }\end{array}$ \\
\hline Borrower Connection & $1.444^{* * *}$ & $1.325^{* * *}$ & $1.174^{* * *}$ & $1.166^{* * *}$ \\
& $(0.003)$ & $(0.004)$ & $(0.004)$ & $(0.004)$ \\
Constant & $0.801^{* * *}$ & $1.201^{* * *}$ & $1.886^{* * *}$ & $1.603^{* * *}$ \\
& $(0.003)$ & $(0.005)$ & $(0.007)$ & $(0.006)$ \\
$N$ & $1,339,089$ & 932,081 & 648,496 & 606,427 \\
$R^{2}-a d j$ & 0.16 & 0.17 & 0.11 & 0.12 \\
\hline \hline
\end{tabular}




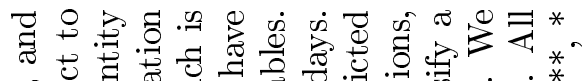

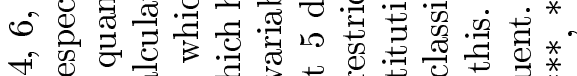
人

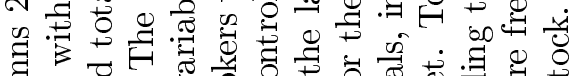

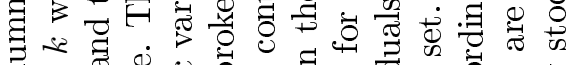

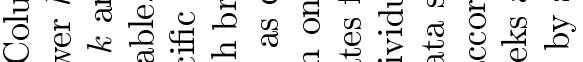

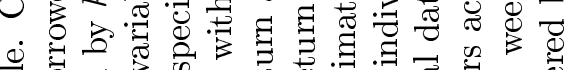

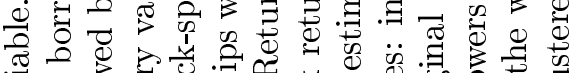

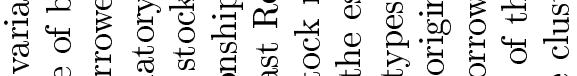

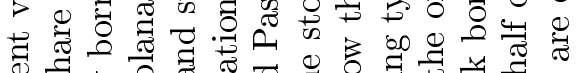

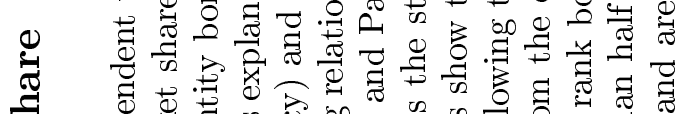

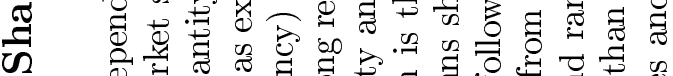

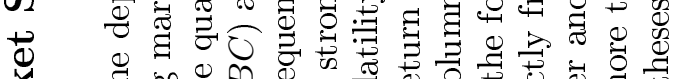

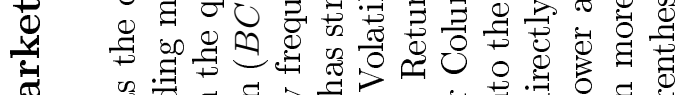

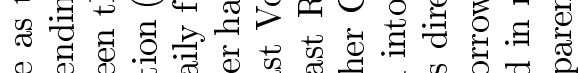

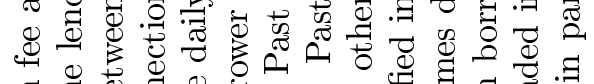

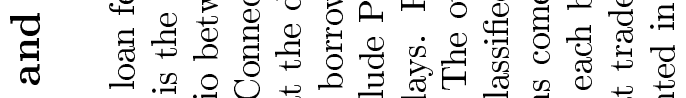

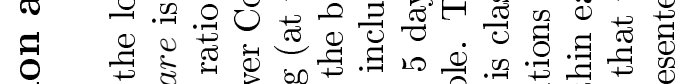

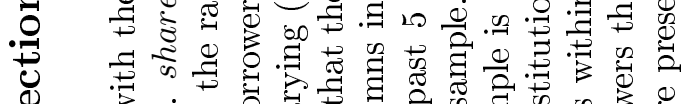
उ.

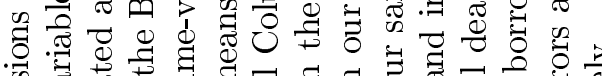

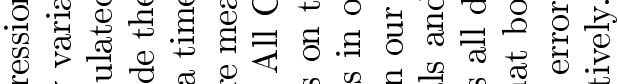

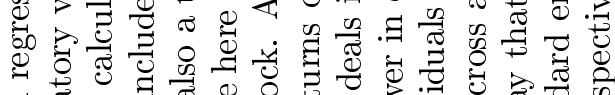

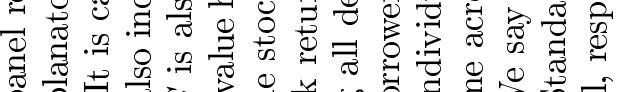

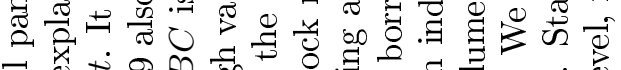

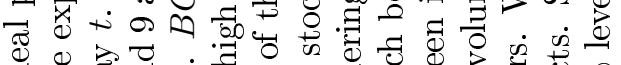

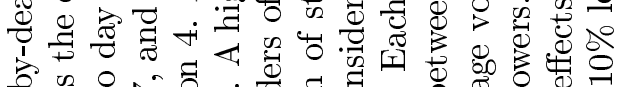
定宁 बే पे च

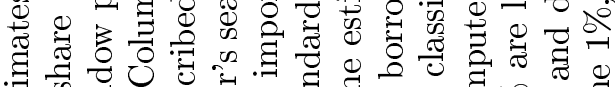

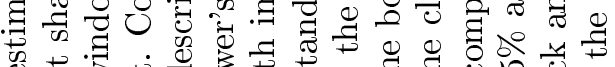

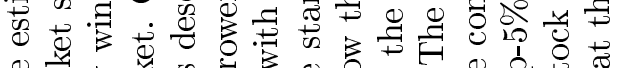

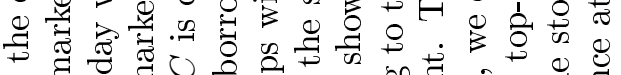

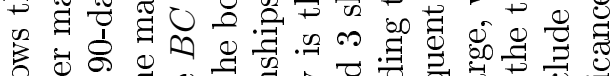

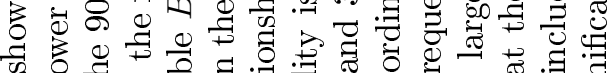

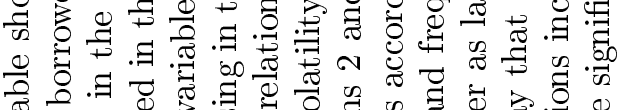

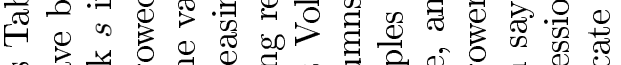

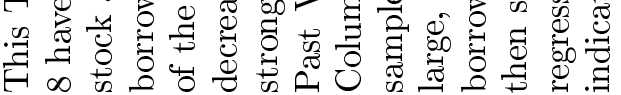

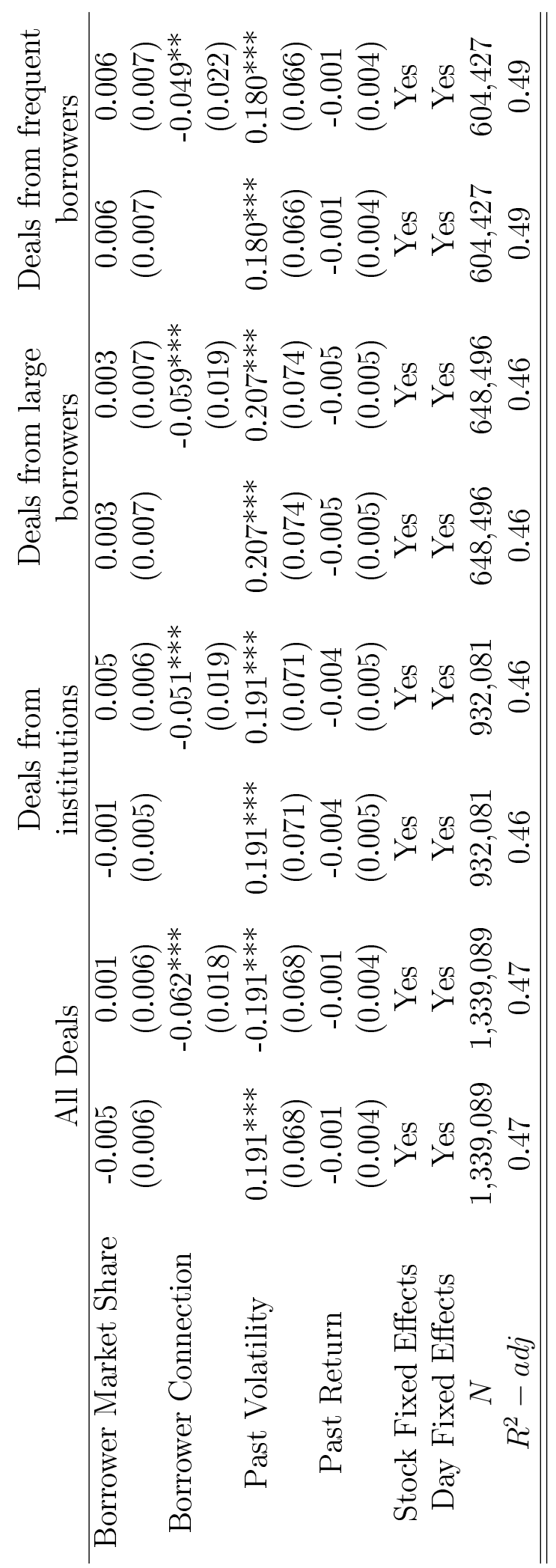




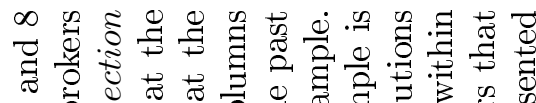
$\sigma$ ఠ

म류 八西

婙

घ્વ ல

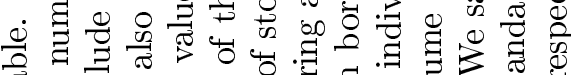

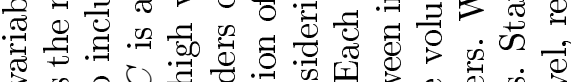
Q

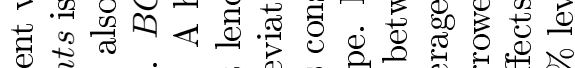

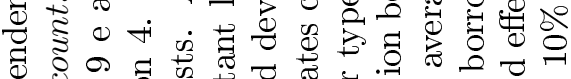

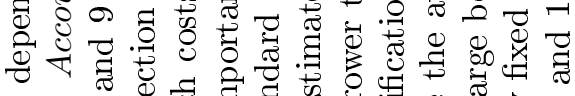

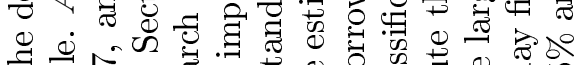

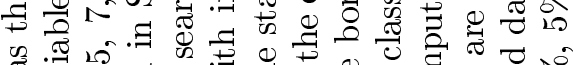

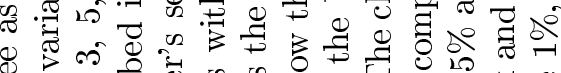
20 은

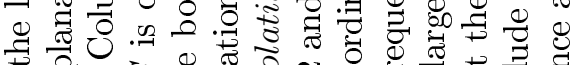

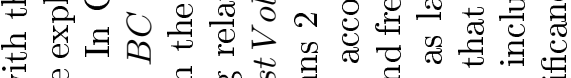

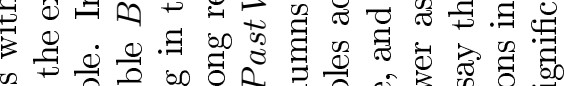

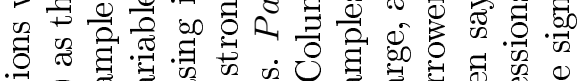

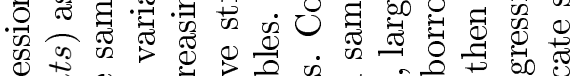

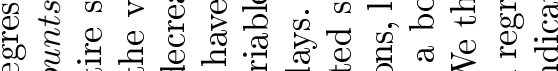

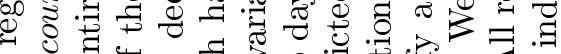
중

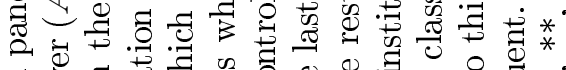

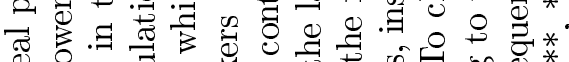

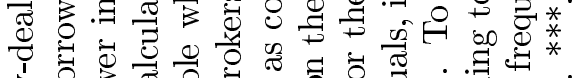

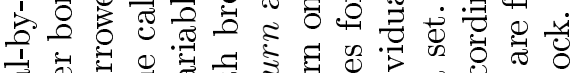

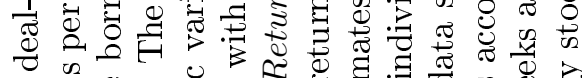
o g.

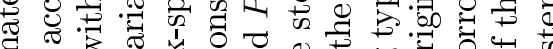
ह

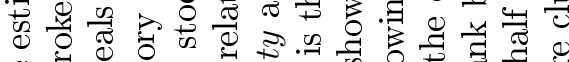

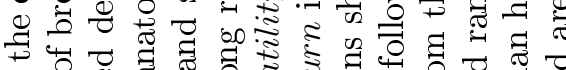

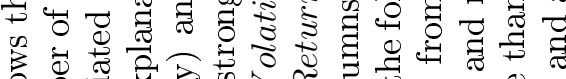

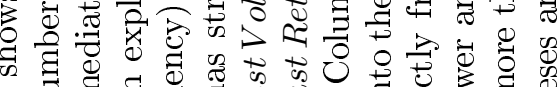
을

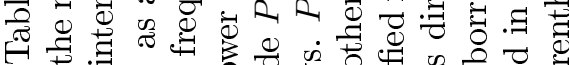

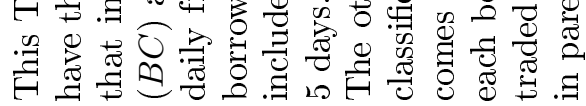

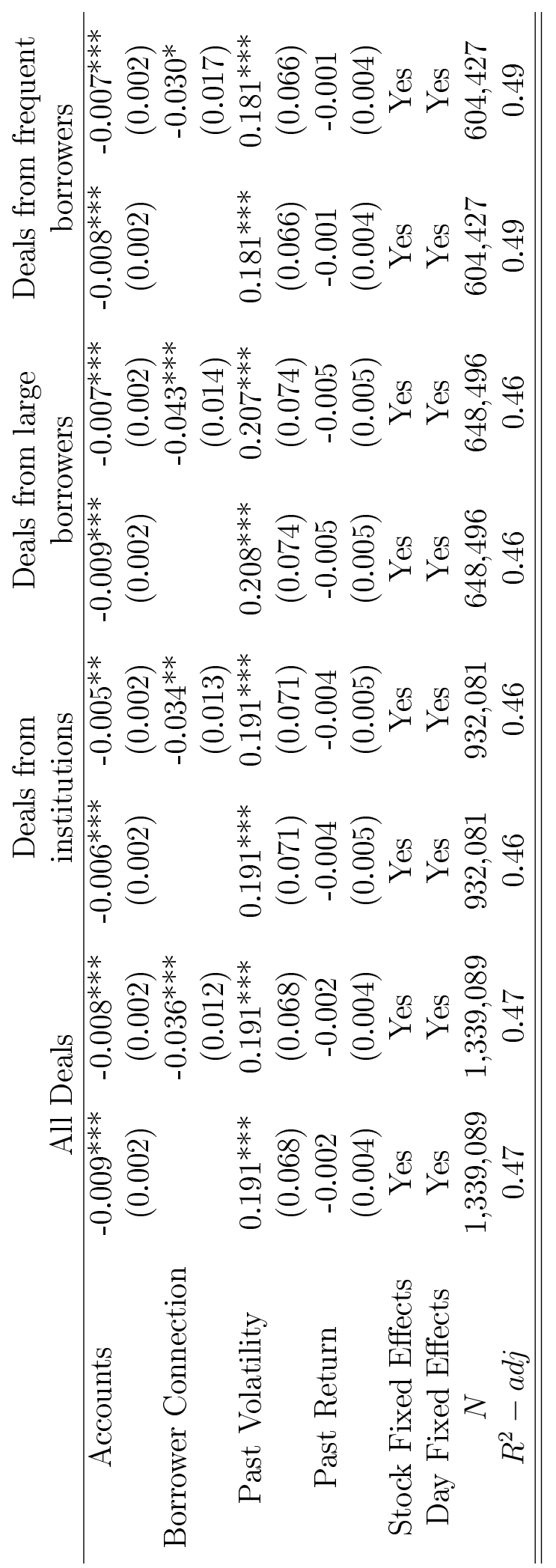




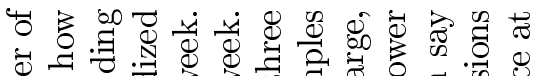

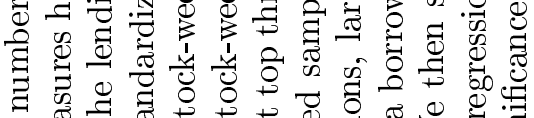

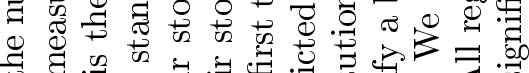

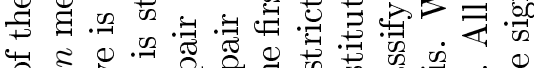
बี 嵌 क Oे

की

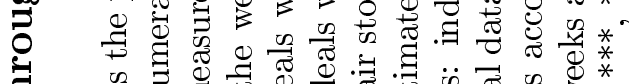

索

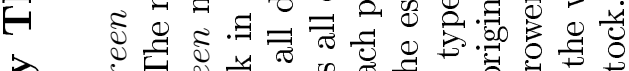

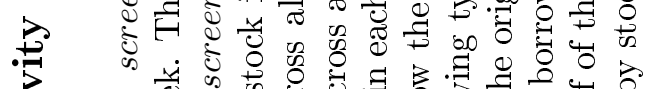

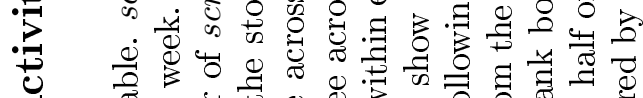

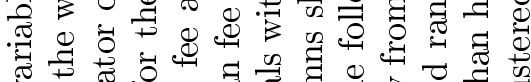

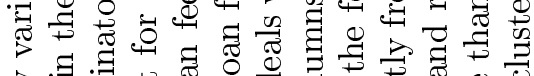

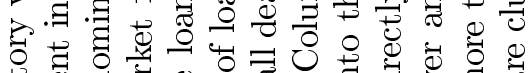

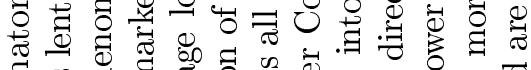
สี

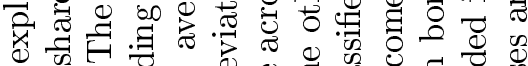

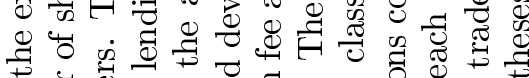

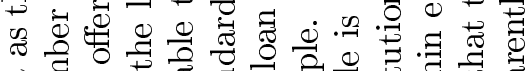

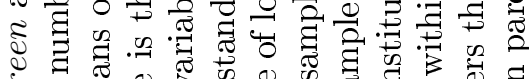

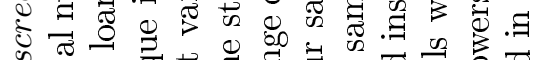

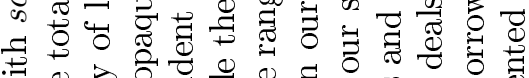

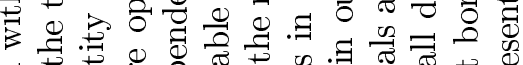

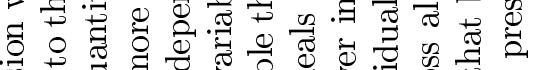

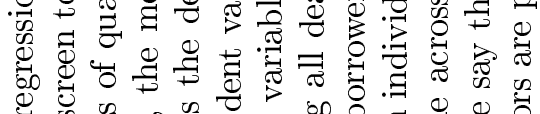

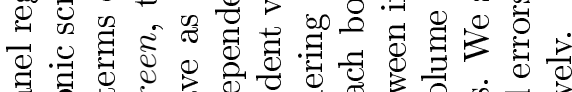

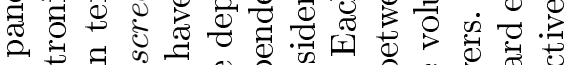

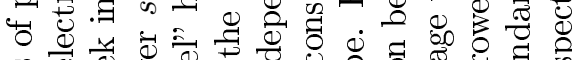

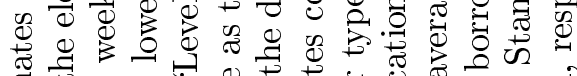

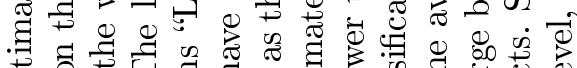

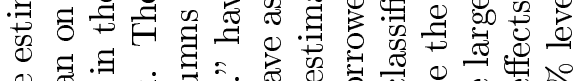

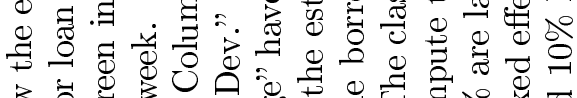

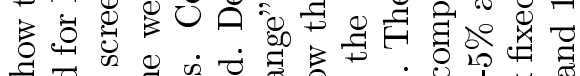

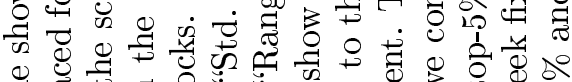
更

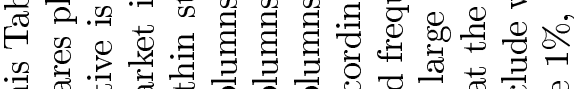

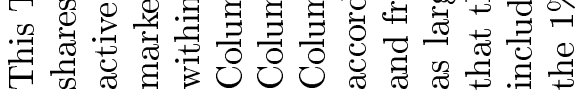

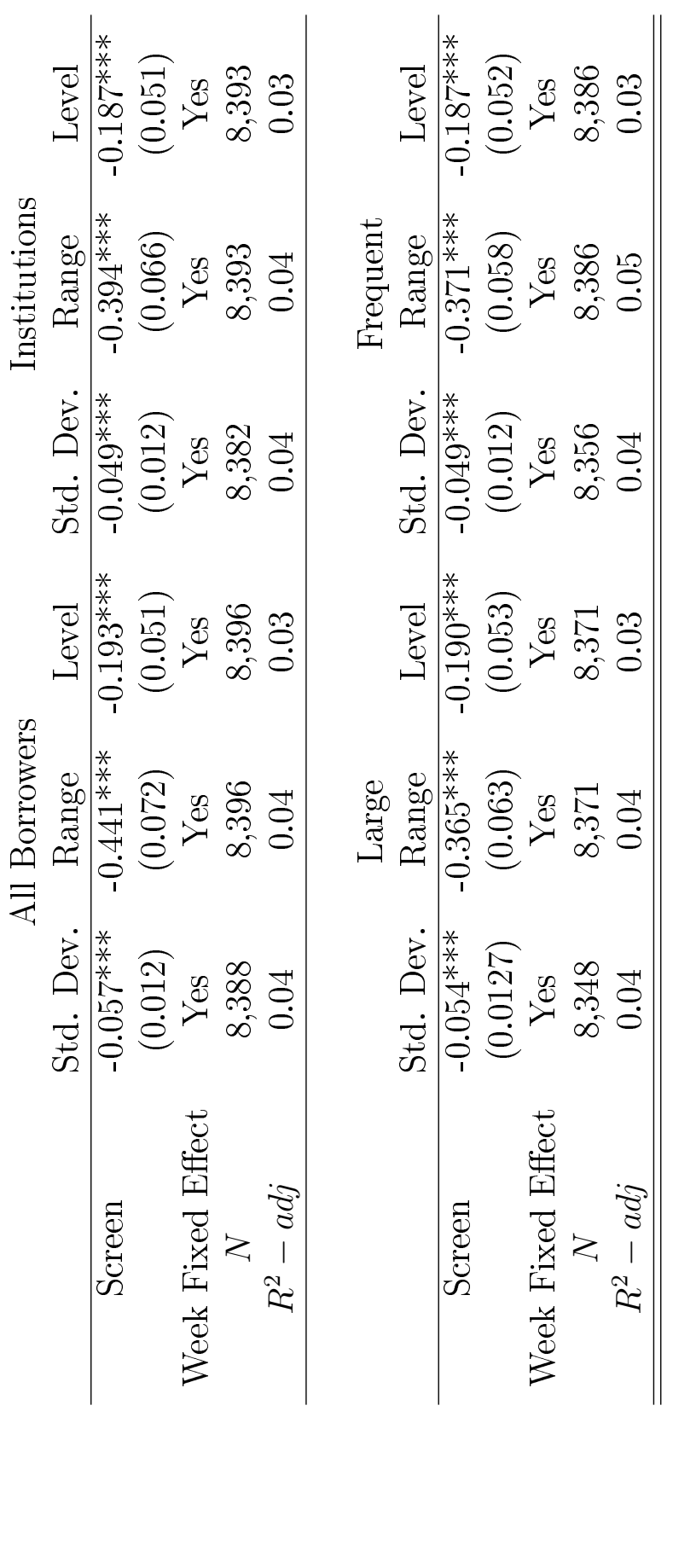

